\title{
Recent Progresses of Superhydrophobic Coatings in Different Application Fields: An Overview
}

\author{
Yuxing Bai ${ }^{1}$, Haiping Zhang ${ }^{1, *}$, Yuanyuan Shao ${ }^{1}{ }^{10}$, Hui Zhang ${ }^{2, *}$ and Jesse Zhu ${ }^{2}$ \\ 1 Collaborative Innovation Center of Chemical Science and Engineering (Tianjin), School of Chemical \\ Engineering and Technology, Tianjin University, Tianjin 300072, China; byx10190809@tju.edu.cn (Y.B.); \\ yshao@tju.edu.cn (Y.S.) \\ 2 Department of Chemical and Biochemical Engineering, The University of Western Ontario, \\ London, ON N6A 5B9, Canada; jzhu@uwo.ca \\ * Correspondence: hpzhang@tju.edu.cn (H.Z.); hzhang1@uwo.ca (H.Z.)
}

check for updates

Citation: Bai, Y.; Zhang, H.; Shao, Y.; Zhang, H.; Zhu, J. Recent Progresses of Superhydrophobic Coatings in Different Application Fields: An Overview. Coatings 2021, 11, 116. https://doi.org/10.3390/ coatings11020116

Academic Editor:

Ioannis Karapanagiotis

Received: 21 December 2020

Accepted: 16 January 2021

Published: 20 January 2021

Publisher's Note: MDPI stays neutral with regard to jurisdictional claims in published maps and institutional affiliations.

Copyright: (c) 2021 by the authors. Licensee MDPI, Basel, Switzerland. This article is an open access article distributed under the terms and conditions of the Creative Commons Attribution (CC BY) license (https:// creativecommons.org/licenses/by/ $4.0 /)$.

\begin{abstract}
With the development of material engineering and coating industries, superhydrophobic coatings with exceptional water repellence have increasingly come into researchers' horizons. The superhydrophobic coatings with corrosion resistance, self-cleaning, anti-fogging, drag-reduction, antiicing properties, etc., meet the featured requirements from different application fields. In addition, endowing superhydrophobic coatings with essential performance conformities, such as transparency, UV resistance, anti-reflection, water-penetration resistance, thermal insulation, flame retardancy, etc. plays a remarkable role in broadening their application scope. Various superhydrophobic coatings were fabricated by diverse technologies resulting from the fundamental demands of different fields. Most past reviews, however, provided only limited information, and lacked detailed classification and presentation on the application of superhydrophobic coatings in different sectors. In the current review, we will highlight the recent progresses on superhydrophobic coatings in automobile, marine, aircraft, solar energy and architecture-buildings fields, and discuss the requirement of prominent functionalities and performance conformities in these vital fields. Poor durability of superhydrophobic coating remains a practical challenge that needs to be addressed through real-world application. This review serves as a good reference source and provides insight into the design and optimization of superhydrophobic coatings for different applications.
\end{abstract}

Keywords: superhydrophobic coating; multifunctional; performance conformity; field; application

\section{Introduction}

The wettability of surfaces is one of the most important characteristics of solid surfaces [1]. Generally, a superhydrophobic surface is defined as a surface with a high water contact angle (WCA) of greater than $150^{\circ}$, and a low contact angle hysteresis (CAH) or a low sliding angle (SA) (also referred to as roll-off angle and tilt angles) of less than $10^{\circ}$. The surface wetting behavior can be explained by the theoretical models of Young, Wenzel, and Cassie-Baxter (Figure 1). Young's model describes the thermodynamic equilibrium conditions between the solid, liquid and vapor phases on an ideal smooth and homogenous solid surface. For practical applications, the surface roughness and chemical heterogeneity dramatically affect the non-wettability of the solid surface [2]. To explain the effect, Wenzel's and Cassie-Baxter principles are used to evaluate WCA o144f the substrates [3]. In Wenzel's model [4], liquid is allowed to completely penetrate into the grooves, as shown in Figure 1b, while in Cassie-Baxter's model [5], liquid is prevented from penetrating into the pores and the trapped air enhances the non-wetting properties. A water droplet on superhydrophobic surfaces is typically in the Cassie-Baxter state. 
(a)

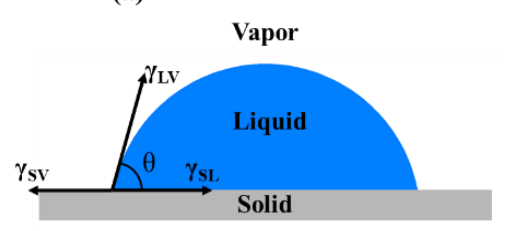

(b)

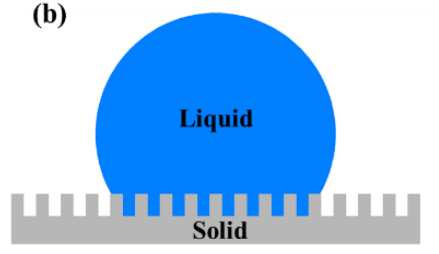

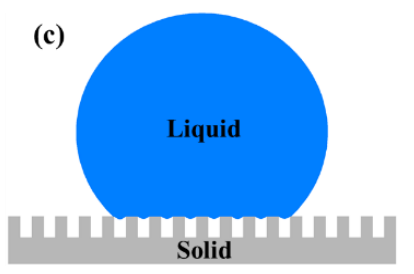

Figure 1. A liquid droplet on different surfaces: (a) Young state; (b) Wenzel state; (c) Cassie-Baxter state (modified from [6]).

In nature, lotus leaves with a high WCA of $161^{\circ} \pm 2^{\circ}$ and low SA of $2^{\circ}$ have one of the most typically natural superhydrophobic surfaces. This excellent self-cleaning property keeps the leaves clean by causing liquid droplets and contaminants to roll and bounce off the surface [7]. The naturally attained superhydrophobic and self-cleaning performances depend on the combination of hierarchical micro/nano rough structure and an epicuticular wax-like material with $26 \mathrm{~mJ} / \mathrm{m}^{2}$ of low surface energy. Inspired by the lotus leaf, artificial superhydrophobic surfaces have been developed by constructing micro/nano rough textures and low surface energy materials. These superhydrophobic surfaces have a broad range of potential application in industries due to multifunctional properties, such as water-repellency [8], self-cleaning [9,10], anti-icing [11], anti-corrosion [12], drag reduction properties [13], etc.

The fabrication of superhydrophobic surfaces usually involve construction of the hierarchical structures followed by modification with low surface energy substances [3]. Many methods can be used to achieve such hierarchical structures, such as templating [14], etching [15,16], anodization [17], electrodeposition [18], self-assembling [19,20], dip-coating [21,22] and spray coating [23,24].

With the recent progress in coating technology, superhydrophobic coatings such as smart coatings have become multifunctional, efficient and versatile and have also gained great interest among researchers worldwide [25]. Such coatings can be applied in all walks of life due to their unique performance. The demands of application in different fields for superhydrophobic coatings are diverse, such as the windshield in the automobile industry and the solar photovoltaic (PV) panels in the solar power sector for self-cleaning purposes, the maritime infrastructures and vessels in the marine field for corrosion resistance, airfoil and empennage in aircraft field for anti-icing, etc.

The reports on superhydrophobic coatings about its preparation, properties, and applications are proliferating every year. However, existing literature lacks related reports on the topic of the application of superhydrophobic coatings based in different fields. In light of the significance of superhydrophobic coatings to key applications with required prominent functionalities and performance conformities, the development of superhydrophobic coatings and their demands in several application fields, including automobile, marine, aircraft, solar energy and architecture buildings are summarized in this paper. The review also discusses the existing bottlenecks that limit industrial application and future trends in the preparation and application of these materials.

\section{Application Fields}

The prominent functional requirements and performance conformities of superhydrophobic coatings in different application fields are shown in Figure 2. The superhydrophobic coatings, fabricated with suitable roughness patterns and low surface energy materials, possess different functional effects in self-cleaning, anti-fogging, anti-fouling, drag-reduction, anti-corrosion, etc. Also, ensuring the superhydrophobic coatings have essential performance conformities by using different fabrication technologies and materials, such as transparency, UV resistance, anti-reflection, anti-water-penetration property, thermal insulation, flame retardancy, etc. has expanded the application to different fields.

In the practical applications of automobiles, solar energy devices, exterior coatings of buildings, a superhydrophobic coating provides a self-cleaning effect which largely decreases maintenance and labor costs, while also prolonging their lifespans. For example, 
solar energy modules are installed at a tilt angle greater than $10^{\circ}[26,27]$, and this angle is generally higher than the maximal sliding angle of superhydrophobic coatings. The resulting rolling water droplets make it possible to realize the self-cleaning feature. There is less attention on and fewer requirements for the self-cleaning effect for marine and aircraft fields. Thus, herein, the self-cleaning application in these sectors is not discussed.

Windshield surfaces are prone to fogging under certain conditions, which obstructs a driver's vision and causes safety issues due to the refraction, reflection and reduction in transmittance of light. Hence, the demand for fog resistance in the application of windshields is essential. A superhydrophobic coating with anti-fogging behavior can prevent water condensation while also accelerating the vanishing of fog.

Corrosion resistance serves as an essential feature for the auto-bodies as well as the maritime infrastructures and vessels in the marine field. Particularly, it puts forward rigorous protection from corrosion in marine applications, where such infrastructures and vessels are exposed to harsh and aggressive environments. The unique hierarchical structure of superhydrophobic coatings minimizes the contact area between surfaces and liquids thanks to the formation of air cushions. As such, the physical isolation of corrosives from metals significantly alleviates the impact from corrosive liquids.

For marine vessels, the frictional resistance from the water accounts for approximately $80 \%$ of the total resistive force consisting of frictional drag and pressure drag $[28,29]$. The drag-reduction property of superhydrophobic coatings can reduce the frictional resistance and thus increase the moving speed, cutting down fuel consumption and $\mathrm{CO}_{2}$ emission.

Furthermore, the adhesion and growth of inorganic scaling, marine micro-organisms, fouling organisms and their metabolites on maritime infrastructures and vessels accelerates corrosive damage, and the fouling also increases the hydrodynamic drag of vessels [30,31]. Thus, it is important to focus more efforts on improving the anti-fouling ability of superhydrophobic coatings.

Ice formation and accretion in cockpit windshields, wings (airfoil and empennage), engines, etc., blurs the pilot's vision, increases flight resistance and causes engine flameout, thus threatening the operation and security of the aircraft $[32,33]$. The ice-repellent properties (anti-icing and icephobic) of superhydrophobic coatings promote the rebound and shed of impinging droplets, delay freezing of the supercooled liquid water and reduce the adhesion strength of ice on aircraft surface.

The superhydrophobic coatings with these functionalities mentioned above meet the featured requirements from different application fields. In addition, the improvements in performance conformities for superhydrophobic coatings bring about better compliance with the essential requirements of coating systems and extend the superhydrophobic coatings to a wider range of actual applications. Importantly, mechanical durability is, more or less, the essential requirement for all application fields.

It is undeniable that superhydrophobic coatings on automobile, marine, aircrafts, solar energy harvesting and architecture-buildings fields are subject to long-term UV exposure under outdoor environments. Thus, UV resistance is a key issue for researchers to take into consideration in order to develop outdoor high-performance superhydrophobic coatings.

Transparency is an essential property of superhydrophobic coatings for their applications on optical surfaces, such as car wind shields, solar photovoltaic (PV) panels and solar collectors. The solar energy modules use sunlight to generate heat and electricity, and thus require a greater demand for light transmission. Superhydrophobic coatings possess an anti-reflective property that serves to avoid unwanted solar energy loss caused by sunlight reflection, thereby improving photoelectric and photothermal conversion efficiency [34,35].

Anti-water-penetration performance is an additional requirement for superhydrophobic coatings applied on maritime infrastructures and vessels, which stay in sea water or a high moisture atmosphere. The water permeation into the hierarchical structure of a superhydrophobic coating may reduce or even disable the anti-drag and anti-corrosion functionalities. More studies on this issue need to be conducted. 
By optimizing superhydrophobic coatings with special performance conformities, such as thermal insulation property and flame retardancy allow a promising development of architecture-buildings field.

The detailed information was elaborated in the following sections.
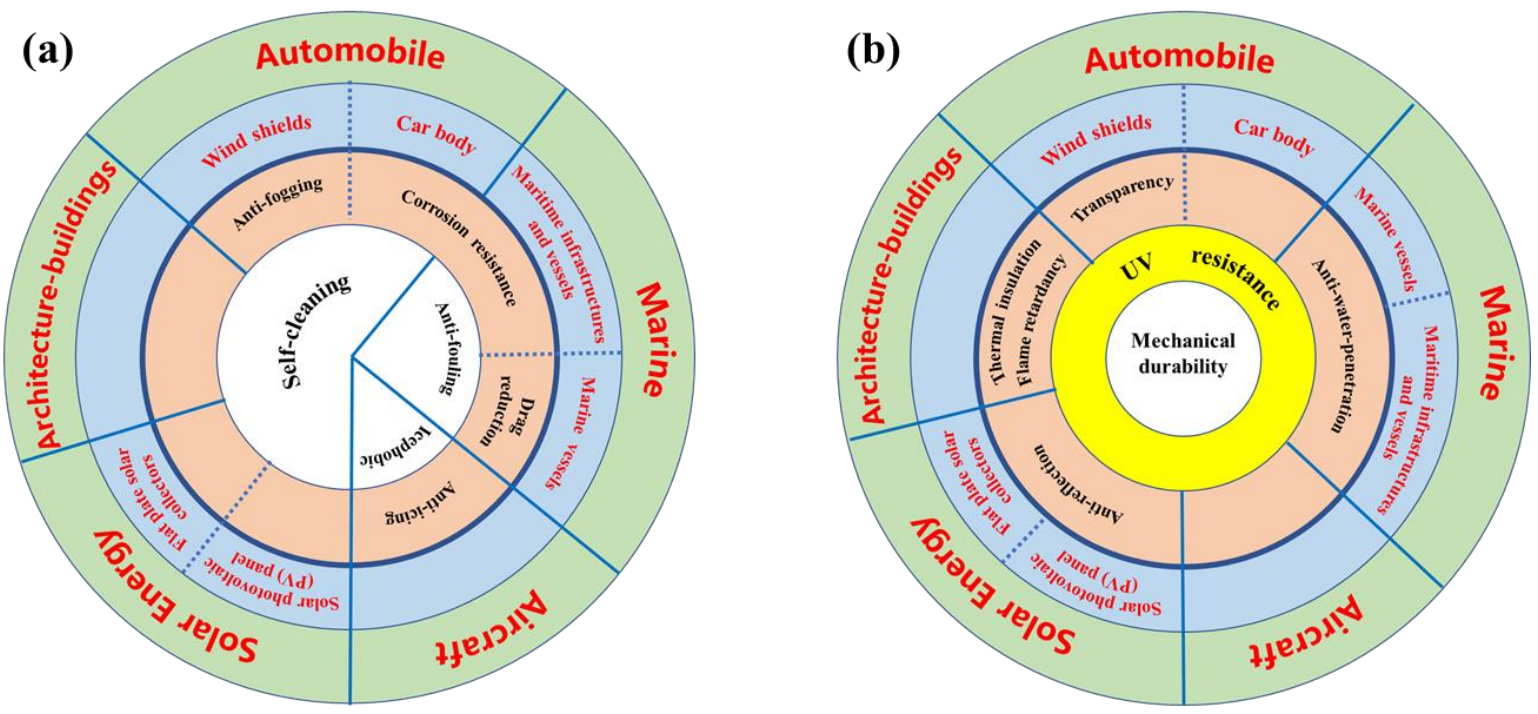

Figure 2. The requirements of prominent functionalities (a) and performance conformities (b) of superhydrophobic coatings in different application fields.

\subsection{Automobile}

Automobiles serve as the main means for transportation in modern times. Designing a corrosion resistant car body (which enhances durability), as well as a clean windshield to ensure clear vision for the driver, are considered increasingly important factors for enhancing automobile security. Multifunctional superhydrophobic coatings applied to the surfaces of the two aforementioned parts are important for maximizing safety, lessening maintenance cost and extending the lifespan of the automobile.

\subsubsection{Wind Shields}

Superhydrophilic coatings possess the ability to eliminate fogging because of the formation of continuous scattering-free water film by a spreading effect. However, these high surface energy materials easily suffer surface contamination. Superhydrophobic coatings with self-cleaning and anti-fogging properties have gained increasing attention in their application to automobile wind shields. It is believed that the anti-fogging feature of the superhydrophobic coatings is caused by the high evaporation rate of tiny fog droplets formed on superhydrophobic surfaces [36]. Also, researchers point out that superhydrophobic surfaces use a rolling mechanism to accelerate fog droplets leaving the surface at a tilt angle [37,38].

In addition, being transparent is the basic consideration of any coatings on top of wind shields. Generally, surface roughness, optical transmittance and superhydrophobicity are competitive properties [39]. When the surface roughness increases, hydrophobicity increases, whereas transparency decreases [40]. The reason for this is that light scattering decreases the transmittance of light, and it is a function of the feature sizes and refractive index of the material surfaces, generally affected by the high dimensions of the roughness features [41]. The combination of micro/nano-structure essential for achieving superhydrophobicity would improve the self-cleaning effect but lead to an opaque surface [42,43]. Methods of combining nanoparticles and low surface energy materials have been reported to construct superhydrophobic coatings without sacrificing transparency of coatings.

Nanoparticles, such as nano-silica $\left(\mathrm{SiO}_{2}\right)$, nano-titanium dioxide $\left(\mathrm{TiO}_{2}\right)$ and nanocalcium carbonate $\left(\mathrm{CaCO}_{3}\right)$ are widely used as surface roughening materials, and alkyl or 
fluorinated organic silanes, polydimethylsiloxane (PDMS)-based polymers and their combinations act as the main reactive molecules used for low surface energy modification [44,45].

PDMS with low surface energy of about $20 \mathrm{~mJ} / \mathrm{m}^{2}$ is used to improve the hydrophobicity of coatings and function as a binder to enhance the durability of coatings due to its characteristics of low surface energy, good chemical stability, high transparency, low reactivity and low-density. Besides, it is more durable and economical than low molecular weight fluorosilanes and chlorosilanes [45-47]. A. Syafiq et al. [48] synthesized a self-cleaning transparent coating by using organic PDMS and Sylgard polymers, inorganic nano- $\mathrm{CaCO}_{3}$ fillers and the aminopropyl triethoxysilane (APTES) binder. PDMS and Sylgard polymers in the coating system were used for surface modification to enhance the hydrophobicity of nano- $\mathrm{CaCO}_{3}$ [49]. The coating system can be cured at room temperature and possesses high transparency with an average transmittance above $82 \%$. Also, the results of the anti-fogging test showed that the large mist droplets appeared on the original glass substrate after $15 \mathrm{~s}$, which was subsequently fully covered after $1 \mathrm{~min}$, while the glass coated with coating still did not show any mist droplets after $3 \mathrm{~min}$, displaying an excellent anti-fog property. Meanwhile, the higher loading of embedded $\mathrm{CaCO}_{3}$ nanoparticles, the higher capillary pressure and air-pockets, which resulted in the great anti-fogging property under extended fog exposure. However, the study pointed out that the hardness of coating decreases with an increase in the loading ratio of nano- $\mathrm{CaCO}_{3}$, thereby producing a surface with higher crystallinity and more brittleness.

Fluorinated silanes chemicals can remarkably reduce the surface energy of coating due to the existence of C-F group [50]. Herein, fluoroalkylsilane $(1 \mathrm{H}, 1 \mathrm{H}, 2 \mathrm{H}, 2 \mathrm{H}$-perfluorooctyltriethoxysilane, PFOTES; $1 \mathrm{H}, 1 \mathrm{H}, 2 \mathrm{H}, 2 \mathrm{H}$-perfluorodecyltriethoxysilane, PFDTES) were discussed to improve the hydrophobic property of coatings.

Lai et al. [51] presented an one-step electrophoretic deposition (EPD) of functionalized titanate nanobelts (TNBs) prepared by combining of hydrothermal particle formation and hydrogen-bond-driven assembly of pre-hydrolysed fluoroalkylsilane (PFOTES) modification of the particle surface to fabricate a stable, transparent cross-aligned superhydrophobic $\mathrm{TiO}_{2}$-based coating on a glass plate. The optimized TNB/FAS coating showed excellent superhydrophobicity $\left(\mathrm{CA} \approx 160^{\circ}\right)$, optical transmittance of $80 \%$ in the most of visible light region and possessed chemical resistance and self-cleaning property in adsorbing contaminants. Moreover, by controlling the deposition time, the work presented a transition between a "sticky" hydrophobic state (high WCA with strong adhesion strength) and a "sliding" superhydrophobic state (high WCA with weak adhesion strength). Also, it is interesting that the superhydrophobic TNB/FAS coating can transform into a porous $\mathrm{TiO}_{2}$ (B) structure with superhydrophilic character after heat treatment. This property can prevent water condensation as droplets on glass substrates [52], exhibiting rapid water spreading ability and anti-fogging ability.

Shang and Zhou [41] reported a transparent superhydrophobic porous-silica coatings on glass substrate through layer-by-layer (LBL) assembly of raspberry-like polystyrene@silica (PS@SiO ${ }_{2}$ ) microspheres, followed by calcination at a high temperature to remove the PS core. The hollow-silica coatings realized a transition from superhydrophilic to supherhydrophobic state after hydrophobic modification with PFDTES using chemical vapor deposition (CVD) method. The developed superhydrophobic porous-silica coatings had self-cleaning ability and high transparency over a broad range of wavelengths. The researchers found that they could improve transparency and superhydrophobicity of porous silica coatings by tuning the number of assembly cycles to obtain the best state. Under two assembly cycles, the superhydrophobic silica coating had a WCA of $159^{\circ} \pm 2^{\circ}$ with a SA of $7^{\circ} \pm 1.5^{\circ}$ and achieved a high transmittance of $85 \%$. Tiny fog droplets were formed on the superhydrophobic coating, and the droplets possessed a large surface area and disappeared after about $10 \mathrm{~s}$ due to the rapid evaporation rate of fog. By contrast, large water droplets were formed on the ordinary glass surface and did not change significantly after $2 \mathrm{~min}$, which would affect the transmittance. It was found that the anti-fogging behavior of superhydrophobic coatings differed from that of superhydrophilic coatings before modification, 
which spreads condensed water droplets into thin water membrane, i.e., forms film-like condensation to prevent fogging due to its excellent wettability. Compared with other anti-fogging superhydrophobic coatings with good anti-fogging performance even in some extreme and hazardous environments, the fabricated superhydrophobic coating had high transparency.

These methods of fabricating water-repellent coatings allow both superhydrophobicity and transparency. Although there exists slight transmittance loss compared to bare glass with the transmittance above $85 \%$, the visibility for these transparent superhydrophobic coating is enough to meet the demand for vision and high security of automobiles.

It is noted that superhydrophobic coatings are water repellent rather than just water vapor repellent [53]. The phenomenon of condensation of water vapor on the surface is caused by the variation of temperature, which below the dew point can disable the water-repellent property of superhydrophobic coatings. Hence, the application of superhydrophobic surfaces for anti-fogging windshields should be further studied.

\subsubsection{Car Body}

The corrosion from a car body's long-term exposure to the outdoors causes a change in performance and shortens the lifespan of the automobile due to physical and chemical interactions with the environment. The phenomenon not only affects the appearance of the automobile, but also engenders damage to related equipment, leading to high maintenance costs and development into a hazard for personal safety. Meanwhile, the manual clean and routine maintenance are time-consuming and laborious. Also, the frequent use of cleaning agent and the impact of water will cause damage to the coating surfaces of the automobile. The superhydrophobic coating serves as a protection layer against corrosive environments, and at the same time it enables the self-cleaning ability of automobile surfaces so that the water droplets can effectively clean the surface because of the high WCA and low SA.

For the corrosion resistance of superhydrophobic coatings, it is generally evaluated by the polarization curves and electrochemical impedance spectroscopy (EIS) in determining the instantaneous corrosion rate of a substrate. In a typical polarization curve, a lower corrosion current density $\left(I_{\text {corr }}\right)$ or a higher corrosion potential $\left(E_{\text {corr }}\right)$ denotes lower corrosion rate $\left(v_{\text {corr }}\right)$ and better anti-corrosion properties $[54,55]$. Also, it is well known that the diameter of the capacitive loop in a Nyquist plots demonstrates the polarization resistance of the working electrode. Higher semicircle diameter represents higher charge transfer resistance, representing better anti-corrosion character [56].

In practical applications, the materials used for car bodies are mainly steel and other lightweight materials such as aluminum and magnesium alloys, etc. The formation of air pockets and reduction of the water contact area of superhydrophobic coatings can serve as a barrier against the corrosion of metal alloys surfaces and weaker adhesion strengths between the contaminants and the superhydrophobic surfaces. Thus, this slows down the corrosion rate and improves the self-cleaning capability of the car body. Hence, superhydrophobic coatings applied on the metal surfaces are suitable candidates for enhancing the anti-corrosion and self-cleaning properties of substrates.

Steel is the basic material that constitutes more than $90 \%$ of the construction of automobiles due to its superior physical and mechanical performances, e.g., high hardness, good castability, high stiffness/weight ratios and high damping capacity, etc. However, steel corrodes easily due to its high chemical and electrochemical activity [55,57]. A lot of effort has been spent towards increasing corrosion resistance of steel substrates, especially in superhydrophobic coatings [6,58].

Qing et al. [55] synthesized a fluorinated polysiloxane (FPDHS)/ZnO nanocomposite coating with a large WCA of $166^{\circ}$, and a low SA of $4^{\circ}$ on the steel substrates using a spray coating method, as illustrated in Figure 3. The FPDHS emulsion was prepared by hydrosilylation reactions and dehydro-coupling of poly(dimethylsiloxane) (PDHS), and dodecafluoroheptyl-propyl-trimethoxysilane (DFTMS). And the FPDHS emulsion was used as the adhesive layer for hydrophobic $\mathrm{ZnO}$ nanoparticles which was modified with stearic 
acid. Additionally, the nanocomposite coating not only had mechanical durability and self-cleaning properties, but also showed better corrosion resistance than the original steel, owing to its lower corrosion current density $\left(I_{\text {corr }}=5.8 \times 10^{-8} \mathrm{~A} / \mathrm{cm}^{2} \mathrm{Vs} 7.9 \times 10^{-6} \mathrm{~A} / \mathrm{cm}^{2}\right.$ of bare steel $)$, corrosion rate $\left(v_{\text {corr }}=6.8 \times 10^{-4} \mathrm{~mm} / \mathrm{a}\right.$ Vs $9.2 \times 10^{-2} \mathrm{~mm} / \mathrm{a}$ of bare steel $)$ and high corrosion potential ( $E_{\text {corr }}=-416 \mathrm{mV} \mathrm{Vs}-890 \mathrm{mV}$ of bare steel). Thus, the as-prepared superhydrophobic coating provided a strategic and promising industrial application in steel substrate corrosion protection.

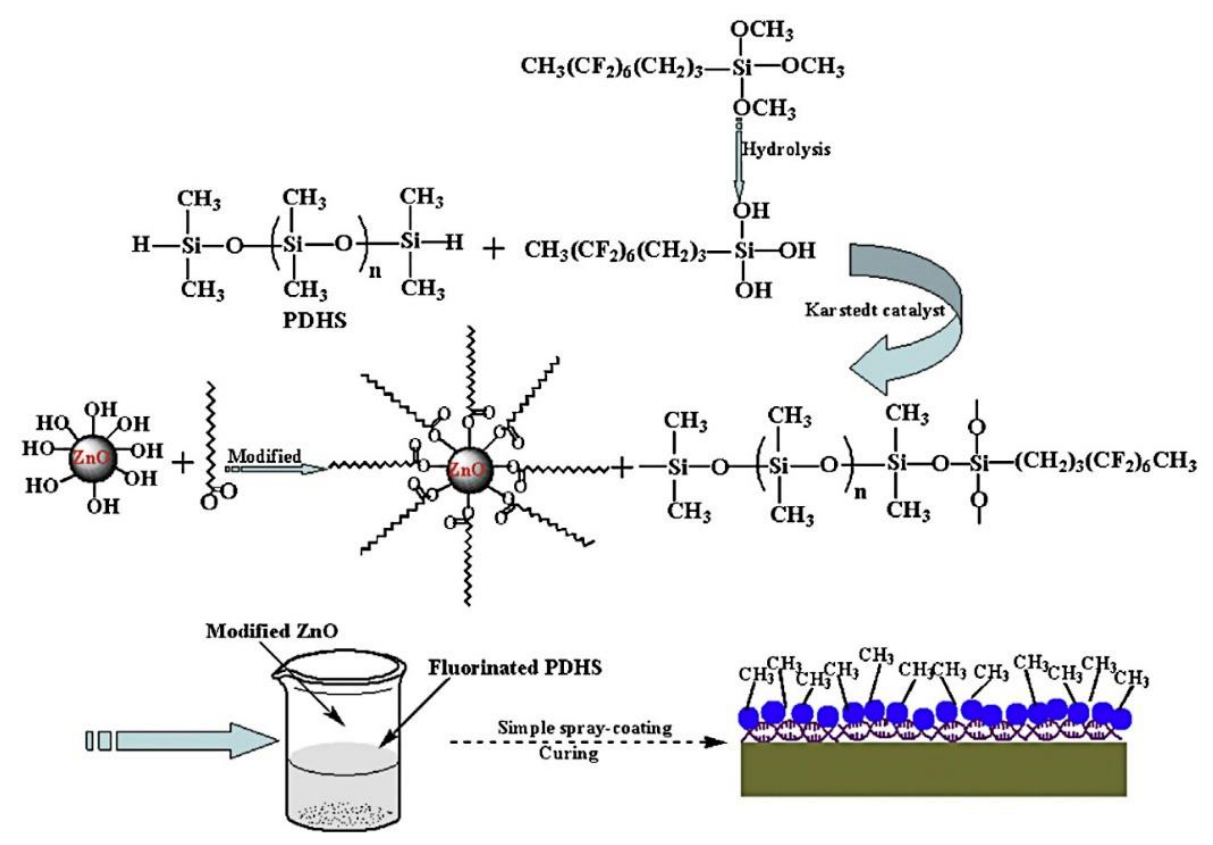

Figure 3. Schematic illustration of FPDHS/ZnO superhydrophobic coating. Reprinted with permission from [55]; Copyright 2014 Elsevier.

Aluminum (Al) alloys are common lightweight engineering materials due to excellent physical properties, machining performance, ductility and cost efficiency, and are universal automobile materials $[59,60]$. However, corrosion of aluminum alloys is inevitable from exposure to complicated atmospheric environments [61]. The fabrication of superhydrophobic coatings extends anti-corrosion and self-cleaning application to Al substrates.

$\mathrm{Lv}$ et al. [62] fabricated a leaf-like copper oxide $(\mathrm{CuO})$ superhydrophobic coating on 6061Al alloy substrate by chemical replacement, thermal oxidation and hydrophobic modification with stearic acid. The developed coatings with WCA of $156.7^{\circ}$ and SA of $3.6^{\circ}$ achieved self-cleaning, mechanical durability proven by validation tests such as tape-peeling, sandpaper-abrasion and chemical stability in acidic and alkaline solutions. Furthermore, the superhydrophobic $\mathrm{CuO}$ coating possessed a higher corrosion potential $\left(E_{\text {corr }}\right)$ of $-0.66 \mathrm{~V}$ and a lower corrosion current density $\left(I_{\text {corr }}\right)$ of $0.77 \times 10^{-7} \mathrm{~A} / \mathrm{cm}^{2}$ than that of bare $6061 \mathrm{Al}$ substrate $\left(E_{\text {corr }}\right.$ of $-0.55 \mathrm{~V}, I_{\text {corr }}$ of $\left.7.18 \times 10^{-7} \mathrm{~A} / \mathrm{cm}^{2}\right)$ after the electrochemical workstation test, which is promising for corrosion protection of $\mathrm{Al}$ alloys.

As one of the most competitive green and lightweight engineering materials, magnesium $(\mathrm{Mg})$ has a high strength to weight ratio, low specific gravity, good impact resistance, mechanical workability, high thermal conductivity and recyclability [6]. Thus, Mg alloys have been widely applied as structural materials for automobiles, aircrafts and electronic products, etc., due to the demand of lightweight and environmental protection $[3,63]$, especially the development of new energy automobiles. However, the corrosion resistance of magnesium alloys is poor, limiting their large-scale application. Thus, using the superhydrophobic coatings to promote corrosion resistance and self-cleaning properties of $\mathrm{Mg}$ alloy substrates have developed into a trending topic. 
Qian et al. [3] prepared a silica-based superhydrophobic coating on AZ31B Mg alloy surfaces using spraying method. In the coating system, nanoscale and microscale silica particles provided the desired dual-scale hierarchical textures, and PFOTES as a fluorine silane coupling agent endowed the silica particles with hydrophobicity. The corrosion current density of the developed superhydrophobic coatings with WCA of $159.4^{\circ}$ and SA of $1.2^{\circ}$ showed a more than four orders of magnitude smaller value and higher corrosion potential $(-1.526 \mathrm{~V})$ than that of bare AZ31B $(-1.577 \mathrm{~V})$, displaying improvement in corrosion resistance. Furthermore, the coating presented mechanical and chemical stability through the abrasion test, immersion test, salt spray test, etc. Chu et al. [64] reported a superhydrophobic coating on AM60B magnesium alloy prepared by the electrodeposition of $\mathrm{Zn}$-Co coating and modification with stearic acid. The fabricated coating with the WCA of $152^{\circ}$ promoted anti-corrosion property of magnesium alloy in $0.1 \mathrm{~mol} / \mathrm{L} \mathrm{NaCl}$ solution with the corrosion current density $\left(I_{\text {corr }}\right)$ decreasing more than three orders of magnitude from $1.23 \times 10^{-5}$ to $3.16 \times 10^{-8} \mathrm{~A} / \mathrm{cm}^{2}$.

Also, to remarkably improve the adhesion strengths between the coating and the substrate, epoxy resin (EP) and PDMS can be used as adhesives to fabricate robust superhydrophobic coatings. As shown in Figure 4a, Li et al. [24] presented a simple, facile,

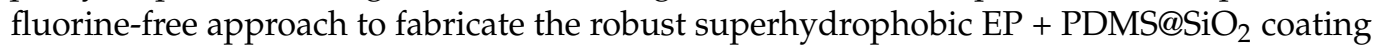
(WCA of $159.5^{\circ}, \mathrm{SA}$ of $3.8^{\circ}$ ) on Mg alloy substrate by spraying an EA-based suspension of the polymers in combination with the functionalized $\mathrm{SiO}_{2}$ nanoparticles. The fabricated coating possessed high-low temperature durability and mechanical and chemical stability. In addition, the coating yielded a value of $1.73 \times 10^{-6}$ for $I_{\text {corr }}$ which decreased by approximately two orders of magnitude compared to original Mg alloys $\left(1.65 \times 10^{-4}\right)$. Thus, the durable coating exhibited superior corrosion inhibition efficiency $\left(\eta_{p}=98.9 \%\right)$, which was the decrease ratio of the $I_{\text {corr }}$ of $\mathrm{Mg}$ alloys coated with superhydrophobic coating compared with bare Mg. Furthermore, the coating in air or oil (dodecane) environments exhibited self-cleaning behavior and superhydrophobicity, as shown in Figure $4 b, c$.

(a)

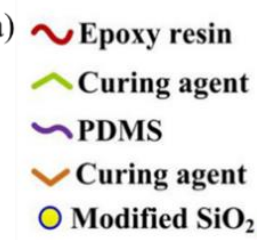

(b)

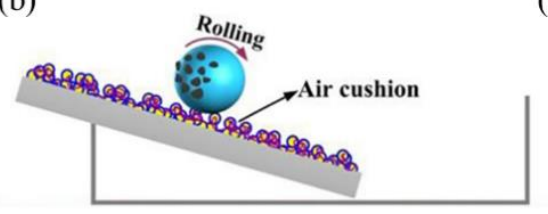

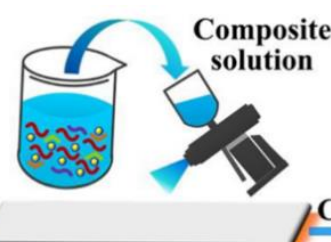

Spraying
Durable Super-hydrophobicity

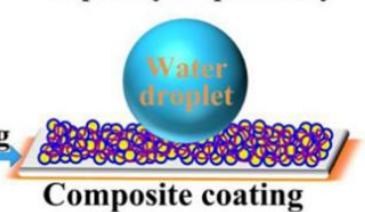

(c)

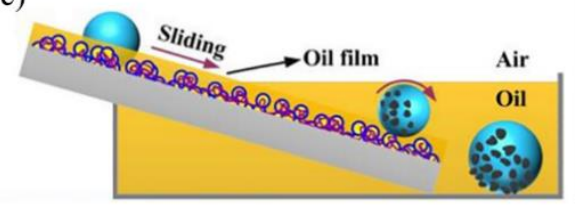

Figure 4. Schematic diagram of the durable superhydrophobic coating fabrication process (a) the selfcleaning processes for the EP + $\mathrm{PDMS} @ \mathrm{SiO}_{2}$-coated $\mathrm{Mg}$ alloy surface in air $(\mathbf{b})$ and oil (c) Reprinted with permission from [24]; Copyright 2019 Elsevier.

\subsection{Marine}

Through the progress of economic development, high energy consumption and corrosion issues inevitably produced by various marine applications have largely affected marine transportation or operations, especially in the harsh marine environment. Many researchers have concentrated on the topic of performance enhancement of marine vessels and infrastructures, which are important systems to meet the highest-level demands in practical marine applications. Herein, superhydrophobic coatings as a key technology can be usefully applied to improve drag-reduction of navigation objects in the water and the anti-corrosion property of marine vessels and infrastructures. 


\subsubsection{Marine Vessels}

The drag reduction of underwater vehicles and surface ships can enhance sailing velocities and effectively save fuel consumption when sailing [65]. Superhydrophobic coatings with excellent water-repellency and low adhesion force to water can be used for various marine vessels, including cargo ships, service ships, navy warships, submarines, etc. Such technology can achieve a drag-reduction effect and improve operating performance with significant advantages in facile fabrication and low energy consumption $[65,66]$. It should be noted, however, that the poor mechanical durability of superhydrophobic coatings, especially in terms of abrasion resistance, limits its practical application in the drag-reduction of vessels. In response to this, many efforts have been devoted to improve the mechanical durability in the drag-reduction effect of superhydrophobic coatings.

Incorporating elastic materials such as PDMS into coating systems can protect coatings from abrasion. Cheng et al. [67] fabricated PDMS/Copper superhydrophobic coatings by incorporating elastic materials (PDMS) and hydrophobic copper particles on a model ship, and gold $(\mathrm{Au})$ superhydrophobic coatings through immersion into $\mathrm{HAuCl}_{4}$ solution to form gold aggregates followed by the modification of $n$-dodecanethiol on model ships wrapped within copper foil. The Au and PDMS/Copper superhydrophobic coatings, respectively, possessed a WCA of $156^{\circ} \pm 1^{\circ}$, with a roll-off angle of $4^{\circ} \pm 1^{\circ}$ and a WCA of $152^{\circ} \pm 1^{\circ}$, a low roll-off angle of $15^{\circ} \pm 2^{\circ}$. Generally, the drag reduction rate was defined as $\left(\left(\mathrm{V}_{\text {superhydrophobic }}-\mathrm{V}_{\text {normal }}\right) / \mathrm{V}_{\text {normal }}\right) \times 100 \%$. The $\mathrm{V}_{\text {superhydrophobic }}$ and $\mathrm{V}_{\text {normal }}$ denote average moving velocity of model ships with and without superhydrophobic coatings. Compared to bare model ship and PDMS/Copper superhydrophobic coatings, the model ship coated with Au superhydrophobic coatings had the highest drag reduction rate of about $32 \%$ but such poor durability that the drag-reducing rate dropped remarkably to almost 3\% after abrasion. However, the fabricated PDMS/copper coating had a $26 \%$ drag reduction rate and only decreased to $24 \%$ after a similar abrasion condition, showing a more durable drag-reducing effect. Meanwhile, the average speed for the PDMS/Copper coating was $0.39 \pm 0.01 \mathrm{~m} / \mathrm{s}$, which was lower than the Au superhydrophobic model ship $(0.41 \pm 0.01 \mathrm{~m} / \mathrm{s})$ but much higher than the bare model ship $(0.31 \pm 0.01 \mathrm{~m} / \mathrm{s})$ at similar sailing experiments.

Dong et al. [65] fabricated a superhydrophobic coating modified by n-dodecanethiol on a macroscopic model ship with a large and curved surface, which was wrapped in copper foil tape, using an electroless deposition of gold ( $\mathrm{Au}$ ) aggregates, as shown in Figure 5. The synthesized coating exhibited a superhydrophobic character with WCA reaching $159.7^{\circ}$, and the model ship with superhydrophobic coating demonstrated a significant drag reduction of $38.5 \%$ at a velocity of $0.46 \mathrm{~m} / \mathrm{s}$. This study provides a new proof-of-principle that can be applied to the reduction of drag in fluid flow and have potential applications for surface ships. However, the study also pointed out that the superhydrophobic coating on practical applications was challenged by its unsatisfactory mechanical durability when in friction with solid surfaces.

In the work of Hwang et al. [13], a superhydrophobic coating using PFOTES, $\mathrm{TiO}_{2}$ nanoparticles and ethanol was described. The surface energy reduction by the superhydrophobic coating weakened the adhesion of water molecules on the sailboat and led to a water drag reduction while increasing its buoyancy on water. Additionally, the researchers fabricated a robust superhydrophobic coating using the paint $\left(\mathrm{PFOTES}, \mathrm{TiO}_{2}\right.$ nanoparticles and ethanol) and adhesive double side tape through layer-by-layer coating. The prepared superhydrophobic surface still caused enhanced buoyancy, water drag reduction and maintained its superhydrophobic property with WCA of $>158^{\circ}$, rolling off an angle and CAH of $<5^{\circ}$ after $100 \mathrm{~cm}$ of sliding friction. Thus, the robust superhydrophobic coating can overcome the damage to its surface from water-friction and undesirable aquatic residues or debris in practical aquatic applications. Meanwhile, the superhydrophobic paint is applicable to various substrates through several common methods, such as dipping, painting and spraying approaches. 


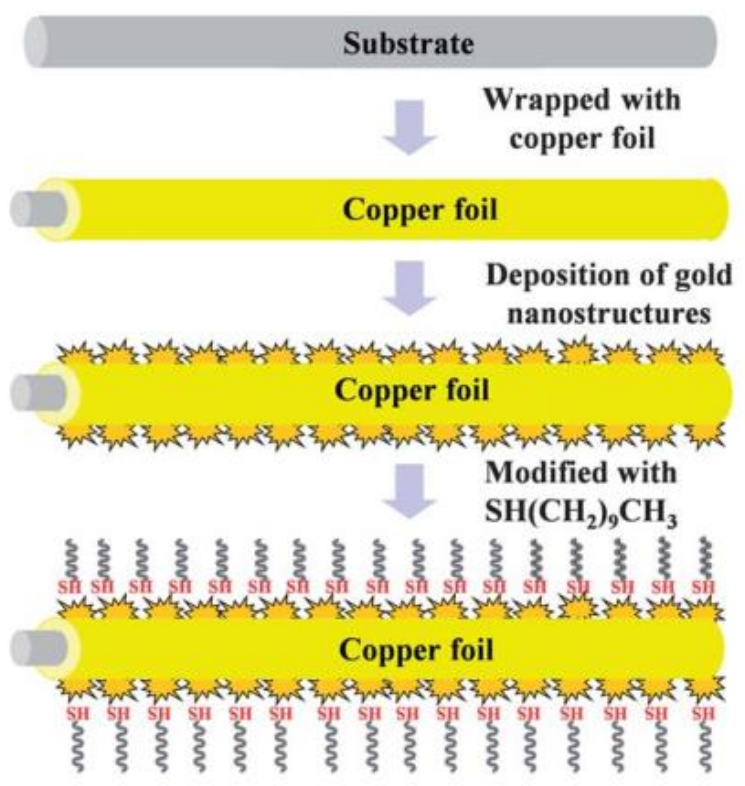

Figure 5. Illustration for the fabrication procedure of the superhydrophobic coating. Reprinted with permission from [65]; Copyright 2013 Royal Society of Chemistry.

\subsubsection{Maritime Infrastructures and Vessels}

Maritime infrastructures, including offshore platforms, undersea construction, pipelines and cables, are critical to the effective functioning of offshore energy and communications systems. However, the higher salinity of sea water causes salt corrosion of these maritime infrastructures and various marine vessels facing harsh marine atmosphere, thereby restricting the service performance and further producing premature failure of metallic components, leading to financial losses, environmental contamination and even sudden accidents $[6,68,69]$. Hence, the proneness to marine corrosion is an important issue and improving the corrosion resistance of these facility surfaces is critical. Superhydrophobic coating, acting as a protective barrier, is one of the effective approaches to improve anticorrosion performance, and its application depends not only on the substrates but also on the feasibility of the treatment techniques [70-72].

Compared to the corrosion atmosphere of the car body mentioned above, the corrosive environments faced by maritime infrastructures and vessels are more aggressive and severe. There are two serious levels of corrosivity categories for maritime installations: C5-M (Coastal and offshore areas with high salinity) and Im2 (Immersed in sea water) [73,74]. The marine environment is notoriously one of the most corrosive and hostile working atmospheres on metal substrates or other materials. Thus, the requirement and demand for the corrosion resistance of superhydrophobic coatings are much higher than that of the car body. On top of the polarization curve and EIS tests, the anti-corrosion ability should also be evaluated by the stability test in which the coated articles are immersed in $\mathrm{NaCl}$ solution for extended periods of time.

Maritime infrastructure and vessel structures are mainly made of steel [75]. For the protection of various of steel-constructions, many researchers have proposed different application techniques to achieve the purpose of fabrication of superhydrophobic coatings with high corrosion resistant quality according to different coating systems.

Aluminum (Al) coatings have been proven to be one of the most economical corrosion protection systems for the marine environment to protect steel materials from corrosion [76]. A composite superhydrophobic $\mathrm{Al}$ coating was proposed by Chen et al. [77]. The synthesized corrosion-resistant superhydrophobic polyurethane (PU) $/$ nano- $\mathrm{Al}_{2} \mathrm{O}_{3}-\mathrm{Al}$ coatings had a static WCA of approximately $151^{\circ}$ and a SA of about $6.5^{\circ}$ through an eco-friendly process. This involved the $\mathrm{Al}$ coatings being initially arc-sprayed onto stainless steel substrate, followed by deposition of $\mathrm{PU} /$ nano- $\mathrm{Al}_{2} \mathrm{O}_{3}$ layer by a suspension flame spraying 
approach. The coating had self-cleaning and anti-corrosion performance with a lower corrosion current density $\left(1.873 \times 10^{-4} \mathrm{~A} / \mathrm{cm}^{2}\right)$ and a higher corrosion potential $(-1.207 \mathrm{~V})$, presenting a lower corrosion rate. In the corrosion protection system, the water-repellent coating possessed the ability to prevent corrosive damage from the $\mathrm{NaCl}$ solutions. And densification structures of the composite coating due to the deposition of nano- $\mathrm{Al}_{2} \mathrm{O}_{3}$ particles and PU layer inhibited the migration and penetration of corrosive ions into the as-sprayed Al coating.

A dual interfacial enhancement method to improve the mechanical durability and corrosion resistance of superhydrophobic coatings in the powder coatings processes was discussed by Zang et al. [23]. They proposed a superhydrophobic EP-PTFE/graphenepolydopamine (GP)-SiO 2 -PFOTES coating with a high WCA of $156.3^{\circ} \pm 1.5^{\circ}$ and a low SA of $3.5^{\circ} \pm 0.5^{\circ}$ on a steel substrate by electrostatic spraying method. The coating had improved mechanical durability which was attributed to a dual interfacial enhancement, combining shear flow and pressure flow during the melt extrusion process and the "glue" action of polydopamine. In the study, the self-polymerization of the dopamine on the graphene surface formed abundant hydroxyl groups, providing a secondary reaction platform. Then, $\mathrm{SiO}_{2}$ nanoparticles were grown in situ on the treated graphene via a sol-gel process to form $\mathrm{GP}_{-} \mathrm{SiO}_{2}$ particles with three-dimensional (3D) structure, as illustrated in Figure 6. The results showed that the nano- $\mathrm{SiO}_{2}$ particles can be uniformly distributed on both convex and flat coating surfaces due to the effect of the lamellar structure of graphene. The formed nano-micro-nano structure of EP composite coating created two protection barriers to prolong the lifespan underwater for hydrophobicity, thereby obtaining a selfcleaning property to sand contaminants, an anti-fouling ability to slurry solution and corrosion resistance. Moreover, the prepared coating was able to retain its high waterrepellency even after being scratched or immersed in $3.5 \mathrm{wt} \% \mathrm{NaCl}$ solution for 60 days, exhibiting a potential application in marine environments. Meanwhile, the EP-PTFE/GP$\mathrm{SiO}_{2}$ - PFOTES coating possessed wear resistance that withstood $10^{5}$ abrasion cycles, with a weight loss of only $54.4 \mathrm{mg}$, and anti-fouling properties that repelled the slurry solution and kept a clean surface even after 20 immersions.

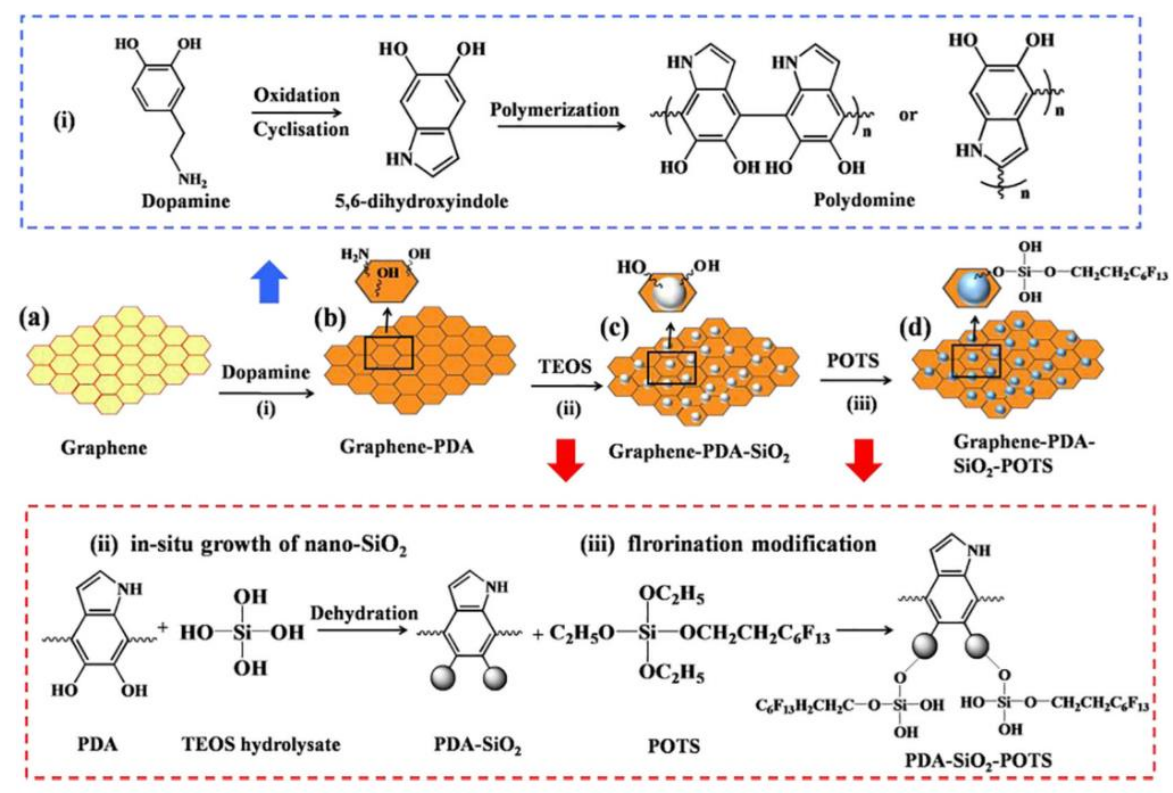

Figure 6. The schematic diagram of the synthesis of $\mathrm{GP}-\mathrm{SiO}_{2}-\mathrm{PFOTES}$ particles. Reprinted with permission from [23]; Copyright 2019 Elsevier.

Aluminum-based materials are also widely used in many marine fields for the construction of ships and maritime infrastructures because of their advantages such as low density and high specific strength [69]. Al5XXX series of Al alloys have been widely used 
in marine industries such as fast ferries and ship building where Al5083 is the most used and most promising aluminum alloy in vessels hull and marine systems. Fahim et al. [78] proposed an economical two-step method to fabricate superhydrophobic coatings on this Al5083 aluminum alloy surface composed of anodizing and chemical modification with two classes of silane. The coating provided a high WCA of $170^{\circ}$ and $160^{\circ}$ and a low CAH of about $3^{\circ}$ and $9^{\circ}$, respectively, by modification with silane of $\mathrm{KH}-832$ and $1 \mathrm{H}, 2 \mathrm{H}, 2 \mathrm{H}-$ perfluorooctyl-trichlorosilane (PFOTS). The work confirmed that the effect of siloxane groups on superhydrophobic properties is more than that of $\mathrm{CF}_{2}$ groups.

Electrodeposition (ED) is an effective process for fabricating superhydrophobic coatings due to its low costs, ease of control and versatility. It can control surface morphology and non-wettability by adjusting the related parameters [79-82]. Zhang et al. [69] reported a handy and universally feasible fabrication of non-fluorinated Allium giganteum-like superhydrophobic aluminum coating via a one-step electrodeposition approach, as shown in Figure 7. The CA value and SA of the ED superhydrophobic coating can reach up to $168.6^{\circ} \pm 2.5^{\circ}$ and lower than $3^{\circ}$ respectively, under the deposition voltage of $30 \mathrm{~V}$. The resultant ED superhydrophobic coating exhibited self-cleaning ability and marine corrosion resistance. Generally, the higher $R_{c t}$ value and lower $Q_{d l}$ value of superhydrophobic coating suggests the lower electrochemical charge transfer process and higher corrosion resistance. The electrochemical results revealed the $R_{c t}$ value (charge transfer resistance) of the ED superhydrophobic coating $\left(5.49 \times 10^{9} \Omega \cdot \mathrm{cm}^{2}\right)$ was five orders of magnitude higher than that of uncoated Al substrate $\left(3.89 \times 10^{4} \Omega \cdot \mathrm{cm}^{2}\right)$, while the $Q_{\mathrm{dl}}$ value (the constant phase elements modeling the capacitance of double-layer) of the ED superhydrophobic coating was four orders of magnitude lower than that of the Al substrate, manifesting an enhanced corrosion resistance and high inhibition efficiency of 99.999\%. Moreover, the ED superhydrophobic coating presented good stability for its superhydrophobicity after being exposed to air for eight months or immersed in $3.5 \mathrm{wt} \% \mathrm{NaCl}$ solution for 12 days.

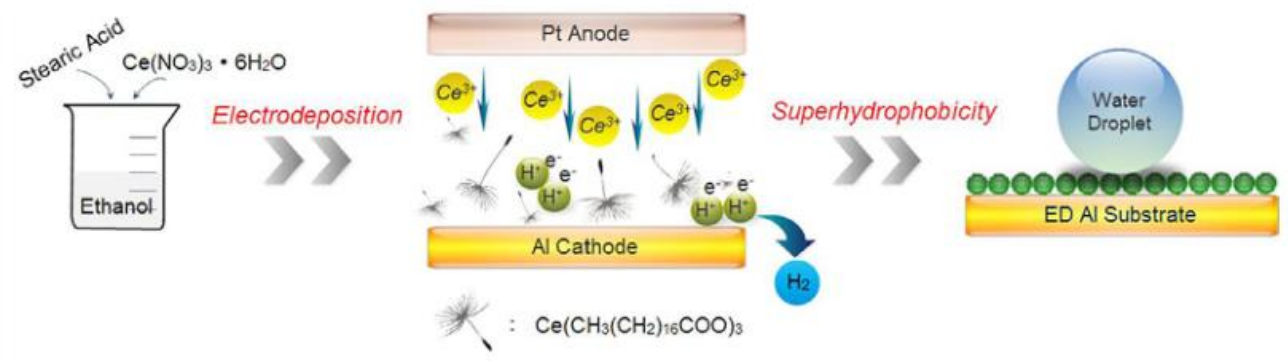

Figure 7. Schematic diagram of nonfluorinated one step fabrication of superhydrophobic coating on EP Al Surface. Reprinted with permission from [69]; Copyright 2018 Elsevier.

These facile fluorine-free fabrication processes of superhydrophobic coatings can realize superhydrophobicity and corrosion resistance, while broadening the potential applications of aluminum-based materials towards maritime infrastructures, vessels, etc., exhibiting great superiority.

Worth mentioning is that the superhydrophobic coating has excellent water repellence but poor water-penetration resistance when being immersed in sea water or a high moisture environment for an extended time. Most of the evaluations of the drag-reduction and corrosion resistance of these superhydrophobic coatings were only conducted for a short time. In this period, the trapped air-pocket serves as a protective barrier to provide drag-reduction and corrosion resistance. In the actual marine environment, however, highsalinity sea water will tardily penetrate into the cavitation and the trapped layer of air will be gradually absorbed by water. The unique hierarchical structure of superhydrophobic coatings may not contribute to, and even inversely affects the function of drag-reduction and corrosion resistance.

Although superhydrophobic coatings possess anti-fouling capability because the entrapped air pockets decrease the contact between fouling and the surface, similarly, 
prolonged immersion of superhydrophobic coatings in the sea water may damage the air layer and even the fouling can enter such surfaces for adhesion and growth $[30,83,84]$.

\subsection{Aircraft}

Most aviation accidents caused by icing occur in airfoil and empennage. Typically, super-cooled liquid water in the clouds that remains liquid below zero and suddenly turns to ice and the existence of tiny pieces of ice are the main sources of icing during a flight. Ice formation and aggregation on an aircraft leads to the damage of equipment and hinders the operation of aircraft, thereby causing aerodynamic stall or even serious hazard [85-87]. For aircraft, the current de-icing and anti-icing systems at cost of huge energy consumption on the ground and during flight, such as thermal, mechanical, or chemical treatment, etc., are not economic and environmentally friendly. They will release chemical substances into the environment, increase fuel consumption and add complexity and weight to the aircraft systems, especially the de-icing process, which needs to take more time and energy $[85,88]$.

Anti-icing and icephobic coatings can be potentially employed to prevent ice formation and reduce ice adhesion strength of aircraft surfaces, respectively. Preventing ice formation is realized by delaying freezing time and lowering freezing temperature of super-cooled liquid water so that condensed water can roll off the substrates before it freezes under external forces including gravity, wind power, centrifugal forces, etc. [89]. The classical nucleation theory revealed that nucleation rate and macroscopical growth velocity of ice can be greatly decreased by a superhydrophobic coating because the trapped air in cavities can cause an extremely low actual contact area and reduce heat transfer between solid surface and liquid, leading to a delay in the time required for freezing [90,91]. Meanwhile, it is also reported that the ice adhesion strength is linearly related to $1+\cos \theta \mathrm{e}$ where $\theta \mathrm{e}$ represents the estimated equilibrium contact angle. The lower the ice adhesion strength, the easier it is to remove ice, which is desirable for de-icing. Thus, superhydrophobic coatings possess a low adhesion strength, showing a good icephobic property [92].

Various fabrication approaches were employed to improve the anti-icing and icephobic performances of superhydrophobic coatings. Herein, some conventional fabrication methods such as spin-coating, sol-gel methods, picosecond laser, suspension plasma spraying, chemical vapor deposition methods and novel fabrication methods such as atom transfer radical polymerization (ATRP) were presented to discuss the feasibility of fabricating anti-icing and icephobic coatings.

In 2017, Ruan et al. [93] prepared a superhydrophobic coating with a WCA approaching $163.6^{\circ}$, using a strategy through spin-coating on aluminum substrate that PTFE was dispersed in composite coating at the ratio of PDMS:TEOS:DOTL:PTFE $=10: 4: 1: 2$. The prepared coatings decreased the starting temperature of ice nucleation by $3.1^{\circ} \mathrm{C}$ so that the ice nucleation starts at -0.5 and $-3.6{ }^{\circ} \mathrm{C}$, respectively, on untreated and coated aluminum plates while achieving a delay of around $50 \mathrm{~s}$ in water drop freezing during the icing process. Furthermore, after 34 icing/deicing cycles conducted in a home-made icing monitoring system, it was observed that the rough surface structure had just minor changes, which led to WCA of $140^{\circ}$. The composite coating simultaneously met the demands of mechanical properties and durability for practical application.

Also, Xing et al. [94] constructed micro-nano tertiary textures via a picosecond laser technique on $\mathrm{Al}$ alloy surface. This method is able to achieve superhydrophobicity without any chemical modifications. These surfaces also displayed an anti-icing property. Theoretical analysis indicated that the laser-processed superhydrophobic surface reduced the liquid-solid contact area compared to the original surface. Not only did this reduce the electrostatic force and van der Waals force, as well as decrease the adhesion energy between solid surface and liquid, but it also moderated the heat loss, which finally enhanced the anti-icing performance of the superhydrophobic $\mathrm{Al}$ alloy surface.

Recently, the suspension plasma spray (SPS) method has been applied to fabricate superhydrophobic $\mathrm{TiO}_{2}$-based coatings that possess high water repellency and durability [95]. Sharifi and colleagues [96] developed a superhydrophobic coating via the SPS 
approach of $\mathrm{a} \mathrm{TiO}_{2}$ feedstock suspension onto grit-blasted substrates. Then, modification of the coating with stearic acid boosted the superhydrophobic behavior with a WCA of $170^{\circ}$, an SA of $1^{\circ}$ and a CAH of $4^{\circ}$. Compared with two commercial superhydrophobic coatings, the relatively thin SPS $\mathrm{TiO}_{2}$ superhydrophobic coating had more excellent anti-icing performance, especially in decreasing the de-icing time and the electrical power required to maintain an ice-free surface. Furthermore, the harder and stiffer $\mathrm{SPS} \mathrm{TiO}_{2}$ coating demonstrated higher durability, which had better resistance to dry particle erosion, multiple icing/de-icing cycles and high intensity water erosion. Although it is slightly less resistant to cloud-sized droplet erosion than one of the commercial coatings-UltraEver Dry (UED) - and similar to the other commercial coating NeverWet (NW), SPS coating can quickly recover superhydrophobicity using a retreatment with the stearic acid solution after suffering from extended water erosion. This is because of its intact and robust hierarchical micro-texture, unlike commercial polymer coatings, which needs thorough removing, cleaning and recoating before reapplying if damaged. The approach mitigates the in-flight icing problem and could be an efficient candidate for anti-icing application on aircrafts.

Liu et al. [97] reported a nano- $\mathrm{SiO}_{2}$-based superhydrophobic coating with a WCA of $163^{\circ} \pm 7.4^{\circ}$ modified by self-assembled monolayers of PFOTES from spin coating and chemical vapor deposition methods. Three parameters affecting icephobicity performance indicated that the icephobic coating was successfully obtained: the bouncing off of incoming water droplets even if the angle inclination is invisible; the icing delay performance that the icing formation on coated surface is $289 \mathrm{~s}$ in contrast to $24 \mathrm{~s}$ for the bare substrates and $204 \mathrm{~s}$ for the commercial icephobic products; and low ice adhesion strength which is desirable for de-icing. The study, however, also pointed out that it needs further optimization to improve durability of the superhydrophobic/icephobic coatings aiming for large-scale application on aerospace.

Wu et al. [98] developed an ice/liquid-repellent, transparent and sol-gel-derived coating with superior performances in transmittance, ice adhesion force, anti-icing accumulation, and self-cleaning performances compared with the well-studied superhydrophobic coatings. The coating exhibited visible-light transmittance reaching $97.8 \%$ and a higher in mechanical strength and durability than the state-of-the-art slippery liquid-infused porous surfaces and polymer coatings. The study suggested that sol-gel-derived coatings with a large percentage of nanoparticles was a good approach for realizing high transparency when the particles are well stirred and dispersed in the sol preparation stage. Furthermore, the transparent icephobic coatings demonstrated the resistance to water condensation and adhesion strength to substrate. The applicability of sol-gel process on substrates with complex shapes and large structures can also realize large-scale application because of its low cost and simplicity. The produced coating realizing superhydrophobic and icephobic properties has the potential for anti-icing protection and self-cleaning applications on aircrafts.

The superhydrophobic coatings fabricated by initiating polymerization from the surfaces of the silica nanoparticles can achieve good durability due to the formation of the covalent bond between the surface and the polymer. In the fabrication process, the fluorinated polymer chains were grafted onto nanoparticles. Atom transfer radical polymerization (ATRP) is attractive in the grafting-from approach because of its tolerance of impurities, mild polymerization conditions and compatibility with various monomers, whereas on the other hand, the requirement for the inert atmosphere of ATRP is challenging $[99,100]$. Therefore, ATRP using activators generated by electron transfer (AGET) was pursued [89,101]. Zhan et al. [89] proposed an anti-icing hybrid material with a high static WCA of $170.3^{\circ}$ and a low CAH of less than $3^{\circ}$ synthesized by grafting fluorinated polymer chains to silica nanoparticles via surface-initiated activators generated by electron transfer atom transfer radical polymerization (SI-AGET ATRP). The schematic illustration demonstrating this is shown in Figure 8. The coating exhibited anti-icing properties, which 
could not only promote the removal of droplets efficiently but also lower the crystallization point and delay the freezing time.

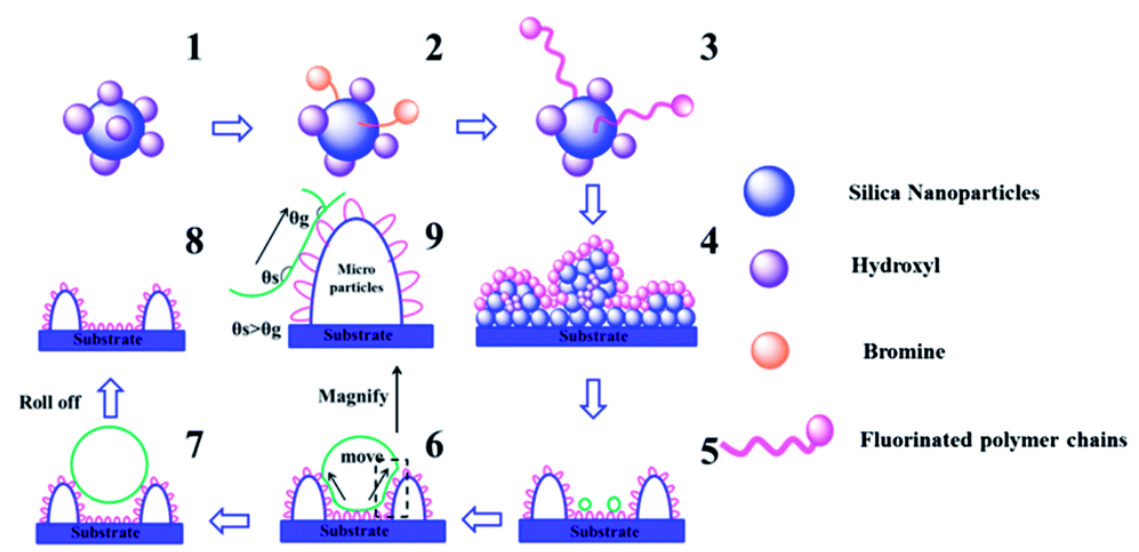

Figure 8. Schematic illustration of the preparation and application of the superhydrophobic anti-icing surface. Reprinted with permission from [89]; Copyright 2014 Royal Society of Chemistry.

Furthermore, these superhydrophobic coatings with anti-icing and icephobic properties can also be applied in some powerplants in cold and humid regions.

\subsection{Solar Energy}

Each year, the quantity $\left(5 \times 10^{24}\right)$ J of power that hits the earth's surface deriving from the sun is 10,000 times higher than the actual annual energy consumption of the whole world. Thus, solar energy has been regarded as the most important sustainable energy resource available due to the year-round abundance of sunlight and the technological advances that exist for capturing the light energy [102]. There are two ways to use solar energy: photoelectric conversion and photothermal conversion. These two processes are usually performed by the solar photovoltaic (PV) panel and solar flat-plate collector, respectively. In practical applications, the accumulation of dust and contaminants on these devices' surfaces largely decrease PV output efficiency and the performance of the solar thermal system, affecting the solar electric and thermal use [103]. Thus, it is desirable to endow superhydrophobic coatings with self-cleaning properties and highlight transmission in solar energy use.

Compared with the visibility requirement for transparency of superhydrophobic coatings in windshield application, solar PV panels and flat-plate collectors require high anti-reflection effect because their conversion efficiencies are closely related to the use rate of sun light. Thus, the researches on these devices mainly focus on the anti-reflective property of superhydrophobic coatings to prevent light scattering and improve light transmittance.

\subsubsection{Solar Photovoltaic (PV) Panel}

Solar photovoltaic technology is the main source of using solar energy due to its safety, pollution-free nature and sustainability $[104,105]$. Solar PV panels as a photoelectric conversion device can convert solar radiant energy into electric energy by the photovoltaic effect, which mainly involves cover glass, ethylene-vinyl acetate copolymer (EVA) adhesive, solar cells, backboard, frame and junction box, as shown in Figure 9. Generally, the reflection of the sun's rays and light scattering by accumulated contaminants (dust, organic waste and water droplets, etc.) on cover glass are the main factors that decrease the efficiency of PV panels [106-108]. Antireflection coatings applied on the cover glass are indispensable to reduce optical losses and thus increase light transmission of PV panel. In addition, the self-cleaning application removes contaminants from the cover glass and improves the transmittance of incident light radiation and the output power of PV panel $[107,109,110]$. Thus, superhydrophobic coatings with self-cleaning and anti-reflective 
properties were carried out to improve conversion efficiency and the optical quality of PV panels.

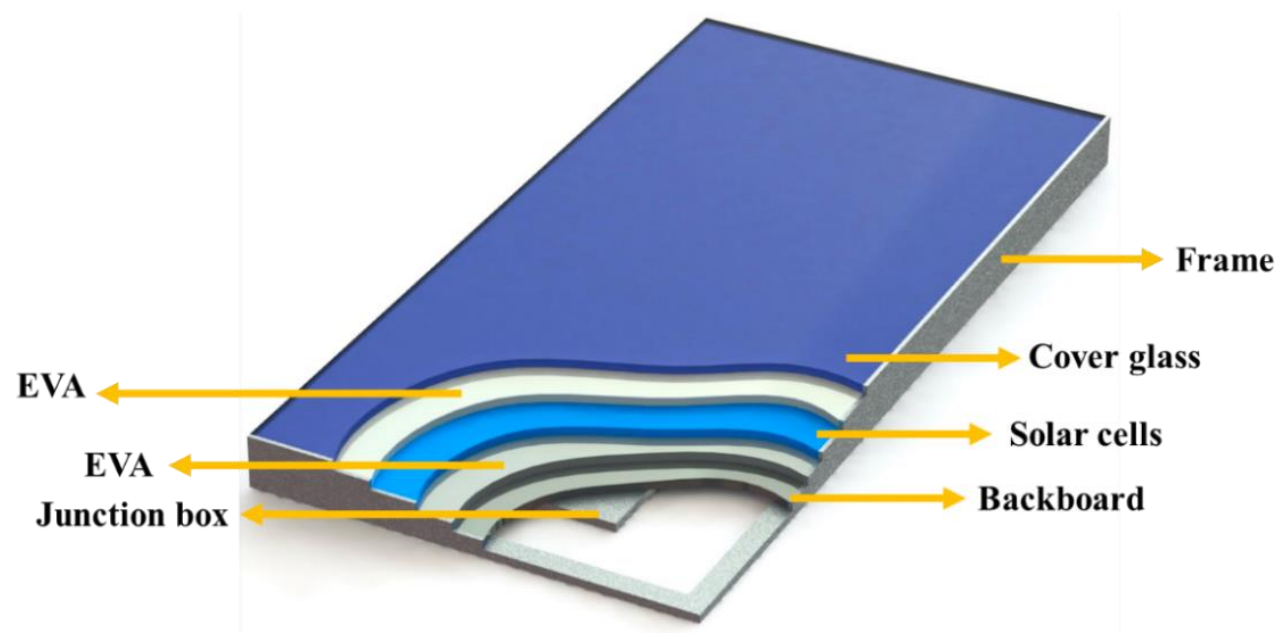

Figure 9. Structural diagram of solar PV panel.

In Figure 10, the research of Zhang et al. [111] indicated that the superhydrophobic coating is effective, particularly for large tilt angled ones, in reducing the effects of dust deposition on solar PV performance. In addition, the superhydrophobic coating had the best performance on dust deposition reduction for the poly-crystalline silicon PV cell, followed by the amorphous silicon PV cell and mono-crystalline silicon PV cell.

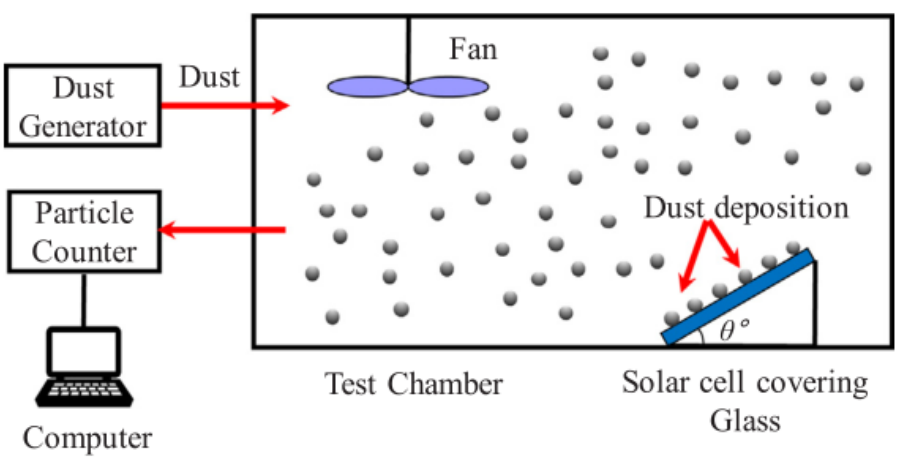

Figure 10. Experimental schematic of dust deposition on solar cell covering glass. Reprinted with permission from [111]; Copyright 2019 Elsevier.

The realization of high surface roughness for preparing superhydrophobic coatings results in light scattering which affects the output efficiency of solar PV panels. Thus, precise tuning of the surface roughness, thickness and control of the refractive index of the coatings is desirable to prevent light scattering and to fabricate the coating that can meet the requirements of both high light transmission and superhydrophobicity [41,112].

The study by Chi et al. [113] found that the addition of organic silica adhesive can attain precise control of the optical transmittance and mechanical strength by adjusting the refractive index of coatings. They explored a simple dip-coating method that enables the fabrication of self-cleaning, antireflection and robust coatings without loss of optical property through nanoscale binding of hydrophobic silica nanoparticles with an organosilica adhesive. During the dip-coating process, the control of coating thickness will affect the light transmission of the functional antireflection coatings, which was achieved by adjusting the withdrawal rates. The developed coating had a WCA of $161^{\circ}$, high transmittance of up to $99.9 \%$ and hardness of $4.2 \mathrm{GPa}$. The paper also reported that the coating could retain the high transmittance under outdoor environments for three months. This was due to 
their excellent self-cleaning property, which made it so that one small water droplet could pick up a large amount of contaminant by its surface. Such a phenomenon was attributed to the high water surface tension and low surface energy of the coatings.

Sutha et al. [114] presented an anti-reflective transparent superhydrophobic coating with a $300 \mathrm{~nm}$ thick nanoflake-like interconnected network with $38 \%$ of porosity based on aluminum oxide coatings on glass substrate through a solution-based method. Herein, aluminum oxide possessed the characteristics of high thermal and mechanical stability, and it could protect from abrasion by wind-borne particles. In addition, the aluminum oxide coating was optically transparent in the visible wavelength regions. The superhydrophobic coating with the gradient porosity profile structure acquired the highest superhydrophobicity (WCA of $161^{\circ}, \mathrm{TA}$ of less than $10^{\circ}$ ) and average transmittance of $95 \%$ by increasing the number of aluminum oxide spin coating layers increased to three ( $\sim 300 \mathrm{~nm}$ thickness). In contrast with uncoated substrate, the superhydrophobic coating showed $2 \%$ improvement in average transmittance with anti-reflective nature. Additionally, the glass substrate coated with superhydrophobic coating recovered the efficiency of the dust contaminated solar PV panel by $91 \%$ after being cleaned with water, which was higher than the recovery efficiency of uncoated glass substrate $(67 \%)$.

Interestingly, Aytug and coworkers [115] suppressed light reflection losses at the glass-air interface over a wide range of wavelengths and incident angles by the formation of antireflective coating with low-refractive index, comprised of an interconnected network of nanoscale pores surrounded by a nanostructured silica framework. The antireflective coating was accomplished by exploiting vapor deposition and metastable spinodal phase separation in low-alkali borosilicate glass coatings. The study indicated that the enhanced optical performance is related to the porosity modulated gradation of the refractive index through the film thickness. Further, the coating had such high superhydrophobicity that the WCA was up to as high as $165^{\circ}$ and TA was less than $5^{\circ}$, and therefore, water droplets could effectively clean the surface. The result suggested that the fabricated coating is available for self-cleaning cover glass of solar PV panel applications. Compared to transmittance of uncoated borosilicate glass template $(\sim 92 \%)$, the nanostructured silica coating remained above $95.2 \%$ on average transmittance, and the coating enables lower reflectance over the entire spectral range.

A superhydrophobic coating with three-dimensional network structure has been fabricated using the dip-coating method through the double-step sol-gel process to improve light transmittance of coating surface by Luo et al. [116] in Figure 11. The developed $\mathrm{PU} / \mathrm{SiO}_{2}$ composite superhydrophobic coating by crosslinking reaction had a high WCA reaching $162.1^{\circ}$ due to the formation of organic whole from the crosslinking reaction of isocyanate $(-\mathrm{NCO})$ of PU with hydroxyl $(-\mathrm{OH})$ on the silica surface to form the carbamate group. Thus, the reduction of hydroxyl $(-\mathrm{OH})$ on the silica surface improved the hydrophobic property of coating. Moreover, the coating had good abrasion resistance under the pressure of $5 \mathrm{KPa}$ because $\mathrm{PU}$ had good adhesive force and structural stability to improve anti-abrasion property. Although the rough surface led to the phenomenon of light scattering, which decreased transmittance, the three-dimensional network structure of $\mathrm{PU} / \mathrm{SiO}_{2}$ coating let the light through, thus having high transparency with a light transmittance of $94.38 \%$ in visible light.

These facile and low-cost methods to fabricate superhydrophobic coatings provide new insights and ideas for self-cleaning and high light transmittance coatings for a promising optical industry, including not only cover glasses of solar PV panel applications but also windshields, window and door glasses, etc.

\subsubsection{Flat Plate Solar Collectors}

Flat plate solar collector, as one of the two major types of solar collectors, is a device that absorbs thermal energy from sunlight and converts it into usable heat. A typical solar collector module mainly consists of cover glass, solar selective absorber (SSA), thermal insulation board, copper pipe, aluminum alloy frame and backboard [117-120], as shown 
in Figure 12. SSA is the core part of the flat plate solar collector, which should possess the characteristic of high absorptivity for solar radiation (high solar absorptance) and low emissivity for thermal infrared radiation (low thermal emittance) for high efficiency [120-122]. However, the dust accumulation on cover glass in practical outdoor environment reduces the transmittance of normally incident light, and thus largely decrease the thermal performance [123]. To increase the efficiency of the solar thermal system, many studies have been concentrated on self-cleaning, antireflective and superhydrophobic coatings on the cover glass. The above studies on the superhydrophobic coatings with self-cleaning capability and high light transmittance coated in the cover glass of solar PV panel can also be applied in the cover glass of flat plate solar collectors.

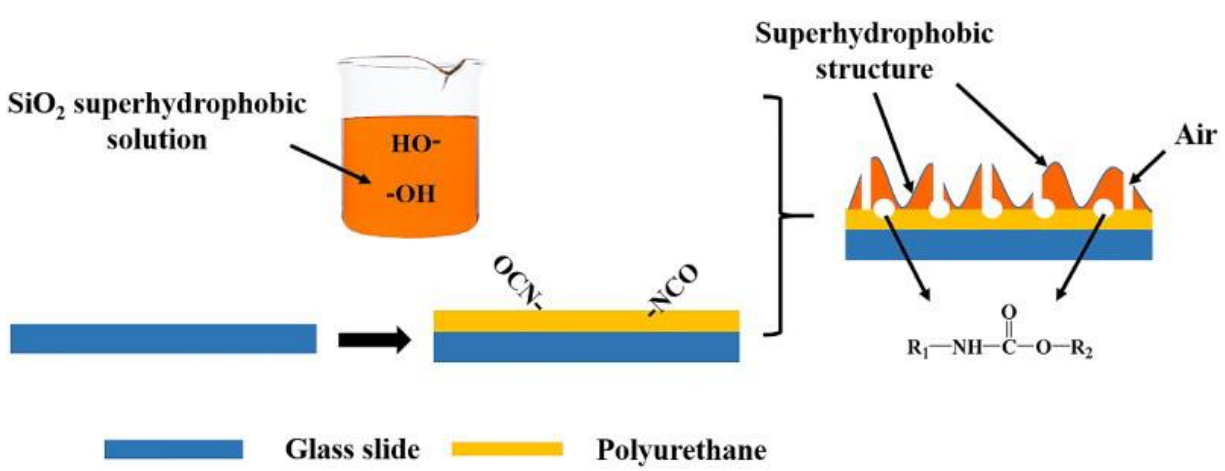

Figure 11. $\mathrm{PU} / \mathrm{SiO}_{2}$ composite superhydrophobic coating forming structure schematic diagram. Reprinted with permission from [116]; Copyright 2018 Informa.

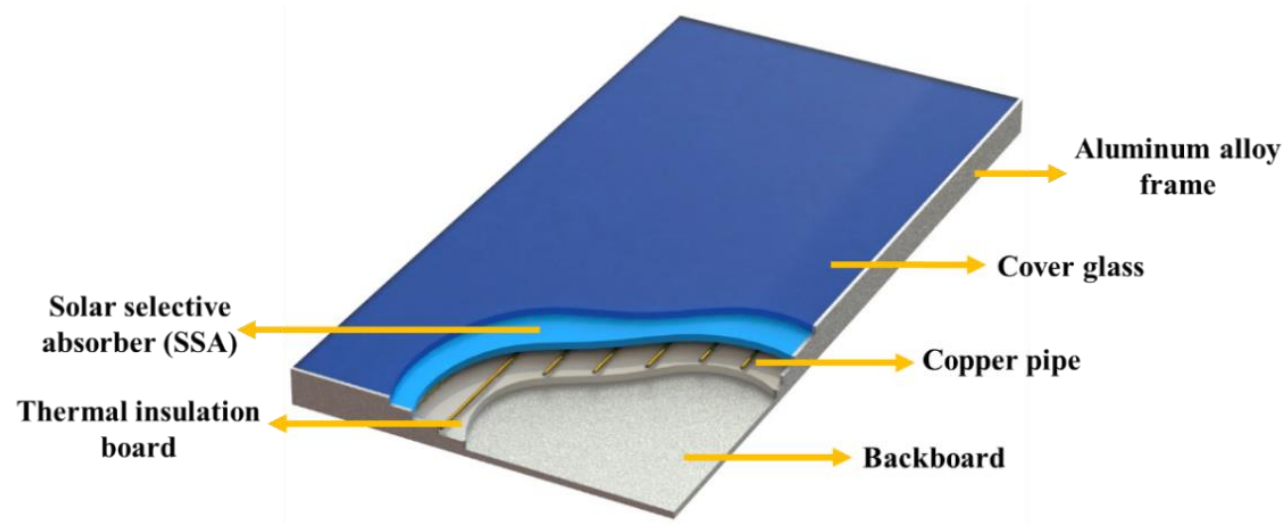

Figure 12. Structural diagram of flat plate solar collector.

Although cover glass is desirable in preventing heat convection loss and preserving heat to obtain high-temperature water in the high-temperature flat plate solar collector, losses caused by reflection and absorption of the cover glass may be higher than heat convection loss in low-temperature applications [124,125]. It is reported that the absorptance of SSA was $95.25 \%$ while that of SSA with borosilicate cover glass above was decreased to $88.50 \%$. Meanwhile, with the borosilicate cover glass, the thermal emittance increased from $1.9 \%$ to $16.7 \%$. These phenomena are attributed to the reflection of incident light on each air/glass interface and partly absorption of the incident light by borosilicate glass [120]. In the work of Zhu et al. [120] the SSA was directly exposed to the outside environment getting rid of cover glass. Based on the low-temperature application of flat plate solar collectors, the study proposed a kind of superhydrophobic coating on SSA without cover glass by a simple sol-gel method. The researchers presented the sandwich structure of "substrate + adhesive +coating" by introducing the organosilicon, as shown in Figure 13, thereby improving adhesion force of coating on SSA and its mechanical strength. The 
coating solved the problems of incident light loss and contaminant accumulation. Meanwhile, the superhydrophobic SSA coating had a WCA of $157^{\circ}$ and an SA of below $2^{\circ}$, and realized a self-cleaning effect via water droplet or tiny wind due to low adhesion strength between contaminant and superhydrophobic SSA coating. After being coated with superhydrophobic coating on SSA, the values of absorption and thermal emittance of SSA became $95.80 \%$ and $1.8 \%$, respectively, denoting that the thermal performance of SSA is nearly unchanged and much better than that of SSA with borosilicate cover glass.

\section{Superhydrophobic coating Organosilicon \\ SSA}

Figure 13. Schematic diagram of the sandwich structure (modified from [120]).

The above as-prepared coating has corrosion resistance, which is suitable for an outdoor environment: after $48 \mathrm{~h}$ neutral salt spray tests, the solar absorptance of bare SSA decreased from $95.25 \%$ to $80.97 \%$, and the thermal emittance increased from $1.9 \%$ to $13.1 \%$. Furthermore, the solar absorptance of SSA coated with superhydrophobic coating decreased from $95.70 \%$ to $89.46 \%$ and the thermal emittance increased from $2.1 \%$ to $12 \%$, presenting a higher corrosion resistance of SSA with superhydrophobic coating than that of bare SSA. Therefore, as suggested by this study, SSA without cover glass and coated with superhydrophobic coating could be an effective method to improve thermal efficiency of flat plate solar collectors at low-temperature application.

\subsection{Architecture-Buildings}

The maintenance of building exterior surfaces is critical to retaining their aesthetic function and extending their service life in practical applications. Especially compared to modern buildings, conservation and restoration of historical buildings consisting of brick, wood and natural stone such as marble, etc. is essential [126-128]. Although cleaning agents, repainting, reinforcement work, etc. can be used to achieve refurbishment to strengthen performance of buildings, including cultural heritage buildings and monuments, these methods are time/material-consuming, labor-intensive and not environmentally friendly.

Atmospheric conditions containing carbon, sulphur and nitrogen oxides together with aerosol particulate matter such as smoke seriously deteriorate building materials [126,128]. Superhydrophobic coatings can be widely applied in the architecture field to aid against pollution due to their excellent self-cleaning properties $[129,130]$. In addition to air pollution, the outdoor environment is the real challenge for the exterior coatings of buildings, which are often affected by temperature change, ultraviolet (UV) radiation, humidity change, mechanical wear, etc. [131,132]. Thus, excellent long-term durability, such as mechanical stability and ultraviolet (UV) resistance, is essential for superhydrophobic coatings to be applied in practical applications of building exterior walls, exterior wall glass, glass ceilings and other building materials. In addition, some superhydrophobic coatings with other special properties, such as thermal insulation property and flame retardancy, have also garnered attention and can broaden the range of applications within the architecture field.

\subsubsection{Superhydrophobic Coatings with Durability}

With prolonged exposure to the outdoor environment, the superhydrophobic coatings applied in the architecture-buildings field may be damaged or chipped off upon scraping by abrasion due to its fragile micro/nano structure [133]. Furthermore, the superhydrophobic coatings inevitably need to survive under real-outdoor conditions such as sunlight (UV) irradiation that may deteriorate the superhydrophobicity of surface layers in ways 
other than mechanical abrasion [134]. Therefore, constructing durable and robust superhydrophobic coatings is essential for their application in the architecture-buildings field. A main fabrication route is that using robust adhesives to improve the adhesion strengths of coatings to substrates while adding functionalized nanoparticles to design robust micro/nano hierarchical structures. Also, the self-healing property achieved by regenerating the surface compositions can improve the mechanical durability and UV resistance of superhydrophobic coatings [23,135]. The self-healing process is thermodynamically driven by minimizing the surface free energy, and thus hydrophobic groups migrate onto the uppermost layer of coating surface, thereby restoring superhydrophobicity.

The flexibility of the coating formulas based on the $\mathrm{SiO}_{2}$ nanoparticles and other materials not only endowed different substrates with superhydrophobicity, but also other practical and functional properties, such as excellent UV resistance. The combination of silica nanoparticles with polyurethane (PU) or epoxy resin can remarkably enhance mechanical durability of superhydrophobic coatings because of their excellent adhesion strength to substrates. Zhi et al. [133] used a spray process to create a translucent superhydrophobic coating on hard glass and copper substrates based on a combination of fluorine-free polymers (PU, epoxy resin) with silica nanoparticles functionalized by hexamethyldisilazane (HDMS). The water-repellent $\mathrm{SiO}_{2} / \mathrm{PU}$ and $\mathrm{SiO}_{2}$ /epoxy resin coatings maintained their superhydrophobicity after $\mathrm{UV}$ radiation for at least $175 \mathrm{~h}$ due to the stability of $\mathrm{SiO}_{2}, \mathrm{PU}$ and epoxy resin agents upon UV exposure, thereby indicating excellent UV resistance. Meanwhile, the coatings showed self-cleaning properties even after contamination by oil in air and mechanical durability suffering knife scraping, hand kneading, tape peeling and compression and release. $\mathrm{SiO}_{2} / \mathrm{PU}$ superhydrophobic coating remained above $150^{\circ}$ of WCA after 35 abrasion cycles while the commercial NeverWet coating became less than $150^{\circ}$ after only 20 abrasion cycles under the same abrasive conditions. The study also pointed out that the $\mathrm{SiO}_{2} /$ polymer coatings have heat resistance up to $150{ }^{\circ} \mathrm{C}$ and chemical durability in exposure to strong acids and bases. After an ozone attack, the coatings transformed from superhydrophobic to hydrophilic, and could be healed by heat treatment with the hydrophobic $\mathrm{C}-\mathrm{H}$ group diffusing to the uppermost layer of coating.

Zulfiqar et al. [136] sprayed the suspension of hydrophobic silica nanoparticles treated with trimethylchlorosilane (TMCS) on three commercially available building materials, brick, marble and glass substrates, using the commercial 3M Super 77 Multipurpose Spray Adhesive as a binder. This fabricates the durable self-healing superhydrophobic coatings and the corresponding contact angles can be as high as $168^{\circ} \pm 5^{\circ}, 166^{\circ} \pm 5^{\circ}$ and $163^{\circ} \pm 2^{\circ}$, respectively. The coating can withstand external damage without a remarkable reduction in its superhydrophobic property, and can recover its superhydrophobicity via a simple acetone treatment because it can help the coating to clean up surface bound sand particles and rearrange the mixture of hydrophobic silica nanoparticles and binder in the damaged area. The binder was soluble in acetone, which contributed to the healing of superhydrophobic coatings.

Aslanidou et al. [127] sprayed the mixture of $\mathrm{SiO}_{2}$ nanoparticles and the emulsion of silane, siloxane and organic polymer onto white marble and grey sandstone to endow both superoleophobicity and superhydrophobicity on the surfaces to effectively maintain a clean and aesthetic appearance. The fabricated coating could realize superhydrophobicity with a WCA in excess of $160^{\circ}$ and a water TA of less than $10^{\circ}$, and meanwhile the coating exhibited superoleophobicity of $\mathrm{CA}$ of $157^{\circ}$ and $\mathrm{TA}$ of less than $10^{\circ}$ to oil by tuning the ratio of $\mathrm{SiO}_{2}$ nanoparticles and the hybrid emulsion. Furthermore, the coating possessed self-cleaning property, mechanical and chemical durability, which can be potentially applied in the protection of building materials.

Zhang et al. [137] fabricated a translucent durable powder coating on metal and glass conductive substrates based on the combination of polymethyl methacrylate (PMMA) resin particles as binder and silica nanoparticles modified by tetraethylorthosilicate (TEOS) and $1 \mathrm{H}, 1 \mathrm{H}, 2 \mathrm{H}, 2 \mathrm{H}-$ Peruorodecyltriethoxysilane (FAS-17) as low surface energy materials using a one-step electrostatic dusting method, as shown in Figure 14. The $\mathrm{SiO}_{2} / \mathrm{PMMA}$ coating 
demonstrated a superamphiphobic property with a WCA of $156.7^{\circ} \pm 4.6^{\circ}$, a SA of $1.0^{\circ}$ and an oil CA of $154.7^{\circ}$, a SA of $1.0^{\circ}$ and self-cleaning property when polluted by oil and sludge powders. Moreover, it also showed mechanical longevity and resistance to acid/alkaline and UV. And the coating retained its hydrophobic property even after 100 cycles of abrasion and 1000 cycles of finger wiping. The fabrication strategy of superhydrophobic powder coating can achieve minimal waste and high efficiency, and meanwhile powder coating contains no volatile organic solvents which is eco-preferable. Furthermore, the corrosion resistance of the developed powder coating needs to be further improved on the basis of this research.
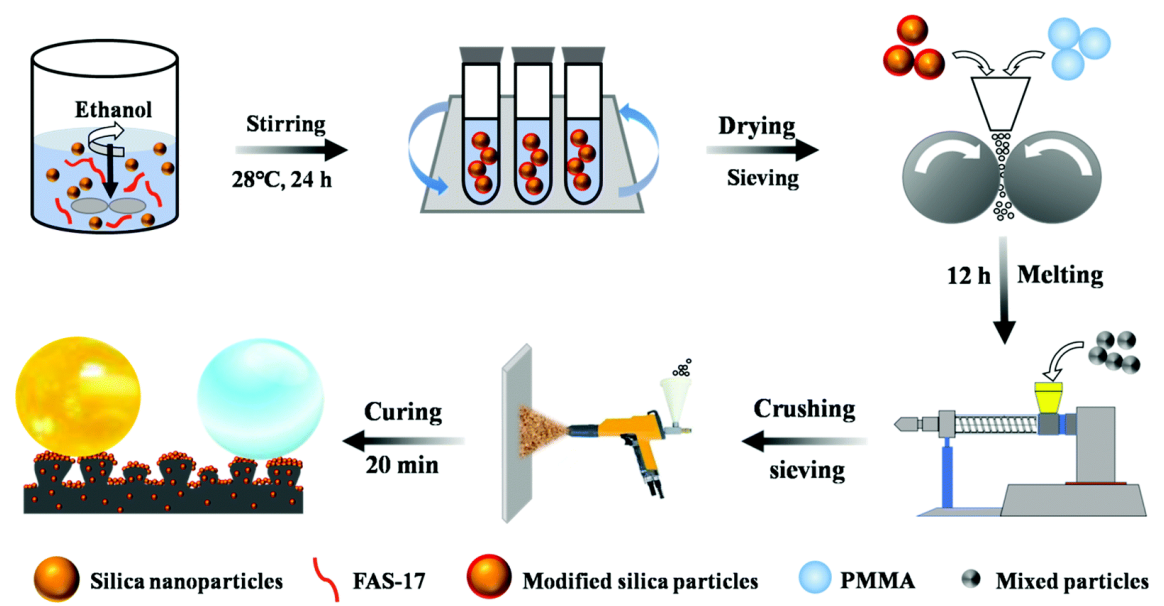

FAS-17

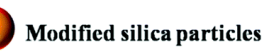

PMMA

Mixed particles

Figure 14. Schematic illustration of fabrication of the wear resistant superamphiphobic coatings. Reprinted with permission from [137]; Copyright 2019 Royal Society of Chemistry.

$\mathrm{TiO}_{2}$ nanoparticles can be used to create the micro/nano rough structure of superhydrophobic coatings and to provide superhydrophobic coatings with remarkable UV resistance due to its excellent chemical, mechanical durability, non-toxicity, ultravioletblocking power and permanent stability under UV exposure [138].

Cappelletti et al. [126] presented a protective polymer coating comprised of a commercial hydrophobic siloxane agent $\left(\mathrm{Alpha}{ }^{\circledR} \mathrm{SI} 30\right.$ ) and $\mathrm{TiO}_{2}$ sol via an airbrush method on the three natural stones used for monuments construction. The prepared coating could realize a high WCA of $155^{\circ}$ in the weight ratio of 3:7 (resin/ $\mathrm{TiO}_{2}$ nanoparticles). After UV ageing test, the $\mathrm{TiO}_{2} /$ resin coating exhibited a good stability in color and hydrophobic property. Exposed to urban polluted air-environment, the prepared superhydrophobic coating possessed an improvement in reducing the degradation of the natural stones (main components: calcium carbonate), owing to the weak affinity between coating and contaminants compared with the pure resin coating.

Wood has been widely used in many novel wood-based buildings, such as in furniture, interior decoration and architectural frameworks due to its economy, recyclability, reproducibility and mechanical strength. Tu et al. [134] reported an approach to fabricate mechanically durable, self-healing and superhydrophobic coating on wood substrate by spraying the perfluoroalkyl methacrylic copolymer $(\mathrm{PMC}) / \mathrm{TiO}_{2}$ nanocomposites onto polydimethylsiloxane (PDMS) precoated substrates, as shown in Figure 15a. The coated wood surface exhibited an exceptional repellence to water and organic liquid with low surface tension, and it was durable enough to withstand repetitive abrasion tests while also exhibiting photocatalytic activity and enhanced photostability under UV exposure. Additionally, in Figure 15b, it is reported that superhydrophobic character of the damaged surface by UV irradiation could be revamped by a heat treatment. This self-healing mechanism is shown in Figure 15c. When the surface hydrophobic PMC was decomposed by UV irradiation with the effect of photocatalytic $\mathrm{TiO}_{2}$ nanoparticles, the exposure of the encapsulated hydrophilic $\mathrm{TiO}_{2}$ nanoparticles resulted in a sticky surface and thus the sliding angle remarkably decreased. Upon a further heat treatment, the PDMS layer serves 
as a hydrophobic reservoir, becoming mobile and migrating onto the surface to cover the exposed hydrophilic $\mathrm{TiO}_{2}$ nanoparticles under thermodynamic drive that minimizes the surface free energy. On the other hand, PDMS is difficult to decompose under UV irradiation, which assures continuous renewal of low surface energy materials and restores the superhydrophobicity of the coating surface.

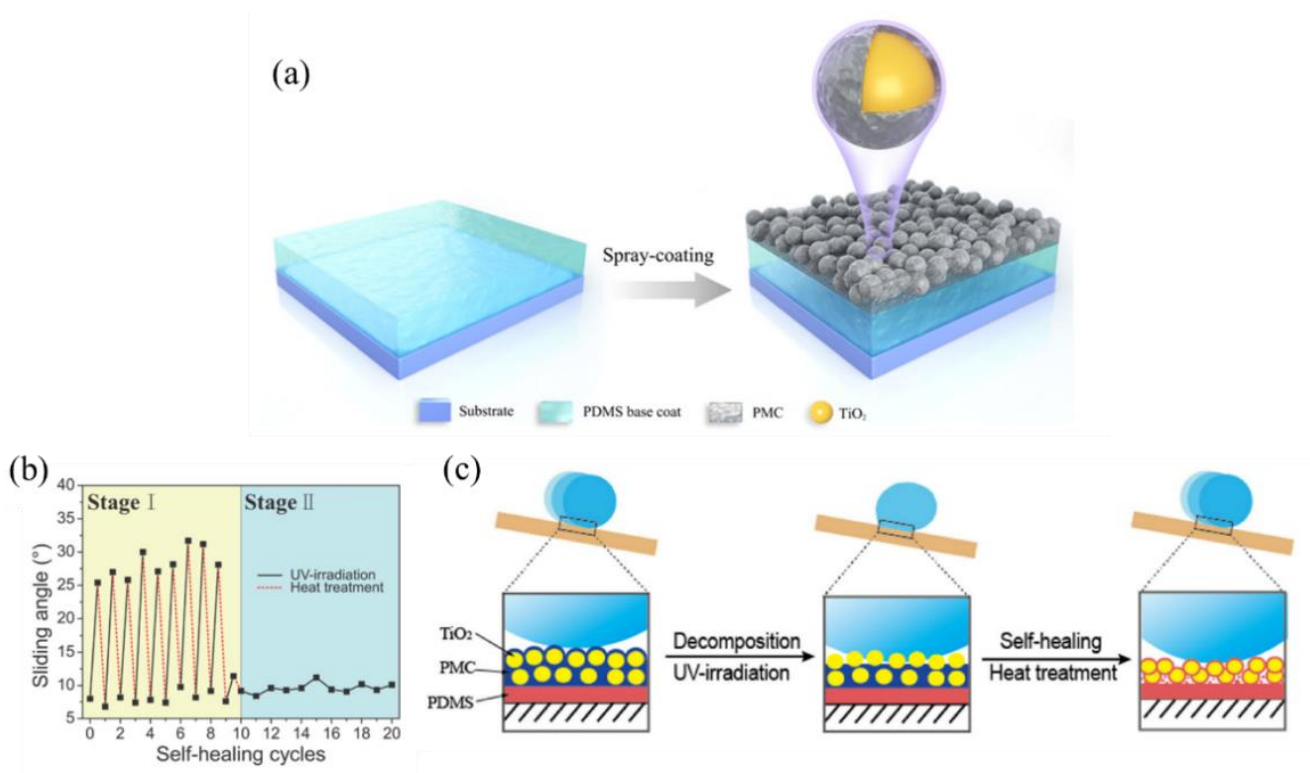

Figure 15. (a) Schematic illustration of the fabrication process; (b) Changes of sliding angle in self-healing process after 20 cycles of 2-h UV irradiation and a subsequent 2-h heat treatment; (c) Selfhealing mechanism of durable superhydrophobic coatings on wood substrates. Reprinted with permission from [134]; Copyright 2017 Elsevier.

Although the self-healing process enhances the durability of superhydrophobic coatings, the treatment approaches, such as heating and organic solvent treatment, are hightemperature (generally under $150{ }^{\circ} \mathrm{C}$ ) and not environmentally friendly, respectively. Regarding the possibility of being applied in the architecture field, it has a long way to go on long-acting superhydrophobic building coatings.

\subsubsection{Superhydrophobic Coatings with Other Special Performances}

Buildings with too high a temperature under solar radiation will result in the increase of building energy consumption, accounting for approximately one-third of total societal energy consumption [139]. Among them, air-conditioning energy consumption occupies the highest proportion, especially during the summer. To broaden the application scope of superhydrophobic coatings in the architecture field, it is necessary to improve the thermal insulation of buildings coated with superhydrophobic coatings and increase energy saving efficiency. Recently, the heat reflective superhydrophobic coatings have played an important role in energy saving for buildings due to their high reflectivity of sunlight, which can be applied in building facades, roofs, etc. [131,139]. These functions are conducive to the long-lasting and stable operation for the exterior coating of buildings, thereby reducing the maintenance cost of the building coatings.

Wang et al. [131] reported a cement-based solar reflective superhydrophobic coating with simultaneously high robustness and self-cleaning ability, which works against various types of damage and pollutants. The coating is based on a mixture of paint solution including white Portland cement (WPC) powder, $\mathrm{TiO}_{2}$ powders, liquid room temperature vulcanized silicone rubber (RTV) as hydrophobic modifier and water as dispersing medium [140]. It was fabricated on diverse substrates via a brush-coating method and the reflective coating presented a WCA of $153.1^{\circ}$ and an SA of $7.8^{\circ}$. In the study, the WPC was used as the gel material due to the superiorities of low cost, good compatibility with 
building materials and high reflectivity to visible light. In the work, $\mathrm{TiO}_{2}$ powder as a solar reflective enhancement filler was used to prepared reflective coatings because of its high reflectivity to both visible and infrared light $[141,142]$. The existence of $\mathrm{WPC}$ and $\mathrm{TiO}_{2}$ powders can largely enhance the roughness of coatings and facilitate the fabrication of superhydrophobic coating. By the method, the infrared reflectance and solar reflectance of the coating reached 0.877 and 0.677 , respectively. The stability of superhydrophobic coating was realized, which can retain its superhydrophobicity after 10 cycles of temperature varying from -40 to $100{ }^{\circ} \mathrm{C}$ and $100 \mathrm{~h}$ of UV exposure. The work provides a reference to optimize and design a long-lasting cooling coating for a building's exterior wall.

As can be seen in Figure 16, Zhang et al. [139] proposed a method to fabricate a dark coating with infrared reflective and superhydrophobic properties by introducing "cool cold" infrared reflective pigment, $\mathrm{SiO}_{2}$ nano-particles and fluorine silicon sol (perfluorodecyltriethoxysilane) into waterborne epoxy resin emulsion and then coating it onto an aluminum plate. The $\mathrm{SiO}_{2^{-}}$" $\mathrm{cool}$ cold" black coatings possessed superhydrophobicity with a WCA and SA of $152.6^{\circ} \pm 0.6^{\circ}$ and $2.8^{\circ} \pm 0.9^{\circ}$, respectively, presenting good self-cleaning property. Also, the coatings had infrared-reflective properties: the average near-infrared (NIR) reflectivity in a NIR region ranging from 780 to $2600 \mathrm{~nm}$ could reach $68 \%$, which presented much larger reflectivity than that of carbon black coatings $(4.5 \%)$ and approached the average reflectivity of $\mathrm{SiO}_{2}$ white coating (73.3\%). Experiencing 20 min irradiation of an infrared lamp, the surface temperature of the coating was $63^{\circ} \mathrm{C}$, which was much lower than that of the carbon black coating $\left(90^{\circ} \mathrm{C}\right)$ and slightly higher than that of the $\mathrm{SiO}_{2}$ white coating $\left(56{ }^{\circ} \mathrm{C}\right)$, showing favorable heat reflective performance. Although dark coatings inherently appear to be inferior in heat reflection by comparison with white coatings, the heat insulating property of the synthesized $\mathrm{SiO}_{2}{ }^{-}$"cool cold" coating was much better than that of ordinary black coating, and even close to that of the white coating. Moreover, the coating can resist water splashing and retain its superhydrophobicity when suffered a continuous heavy rain process reaching up to six $h$, and thus possesses excellent resistance to rain. The prepared superhydrophobic coating with color adjustability, environmental compatibility and NIR-reflection has potential applications in the reduction of building energy consumption and can enhance the self-cleaning property of external walls of buildings. Also, the work provides a better color choice for meeting the demand of new building designs and decorations by simply replacing the color of the "cool cold" pigments. However, compared with general coatings, normally the mechanical performances of the superhydrophobic coatings appear to be much weaker in practical applications.

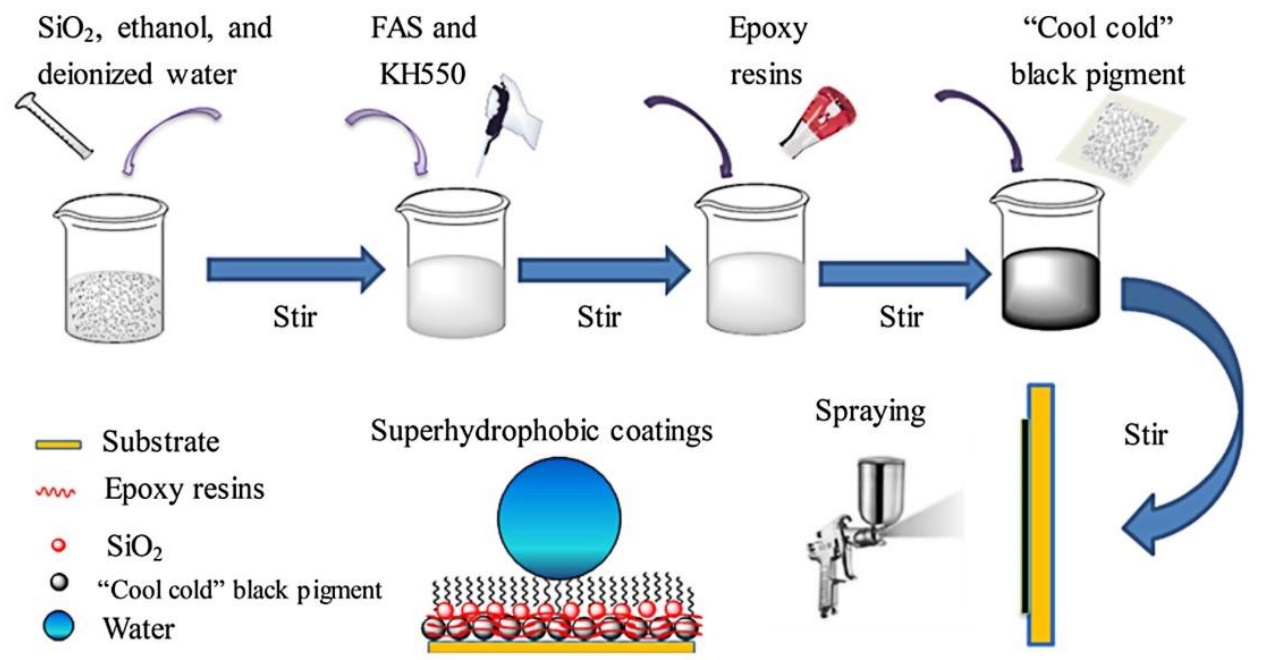

Figure 16. Scheme Outlining the Preparation Process of the Coatings. Reprinted with permission from [139]; Copyright 2018 American Chemical Society. 
Obtaining superhydrophobic coatings with durability and flame retardancy can achieve wide and promising application in waterproof, fireproof materials, superhydrophobic paints, packaging materials, building materials, etc. As illustrated in Figure 17, Wang and Guo [143] conducted a UV radiation method to fabricate a multifunctional superhydrophobic coating with both mechanical durability and flame retardancy on various substrates (glass, wood, cloth, $\mathrm{Cu}$ and $\mathrm{Al}$, etc.) by spraying an all-in-one suspension of different components containing trimethylolpropane triacrylate (TMPTA), vinyltriethoxysilane (VTES), 1H,1H,2H,2H-Perfluorododecanethiol (PFDT), 9,10-Dihydro-9Oxa-10-Phosphaphenanthrene-10-Oxide (DOPO), $\mathrm{SiO}_{2}$ nanoparticles, and 2-Hydroxy-2methylpropiophenone (HMPP). Among them, the fluorinated polymer chain and $\mathrm{SiO}_{2}$ nanoparticles played an important role in endowing the coating with low surface energy and surface roughness, and DOPO as a commonly used fire retardant was utilized to enhance the flame retardancy of the coating. During the fabrication of the superhydrophobic PVDT (PFDT-VTES-DOPO-TMPTA) coating, a UV curing process was performed to break the chemical chains to provoke chemical reactions on the irradiated surface [144]. In a facile combustion experiment, the combustion process of cloth piece coated with PVDT coating exposed to fire was much slower $(\sim 20 \mathrm{~s})$ compared with that of primary cloth piece $(\sim 6 \mathrm{~s})$ and the cloth piece coated with PVT coating without DOPO $(\sim 8 \mathrm{~s})$. Therefore, the PVDT coatings demonstrated flame retardancy and ignition delay. Furthermore, the PVDT coatings showed high repellency to water droplets and self-cleaning effect, which can be controlled by the reactants and the content of nano- $\mathrm{SiO}_{2}$. In addition, their abrasion experiment, tape adhesion test and corrosive media treatment verified the mechanical strength and chemical durability of PVDT coatings.

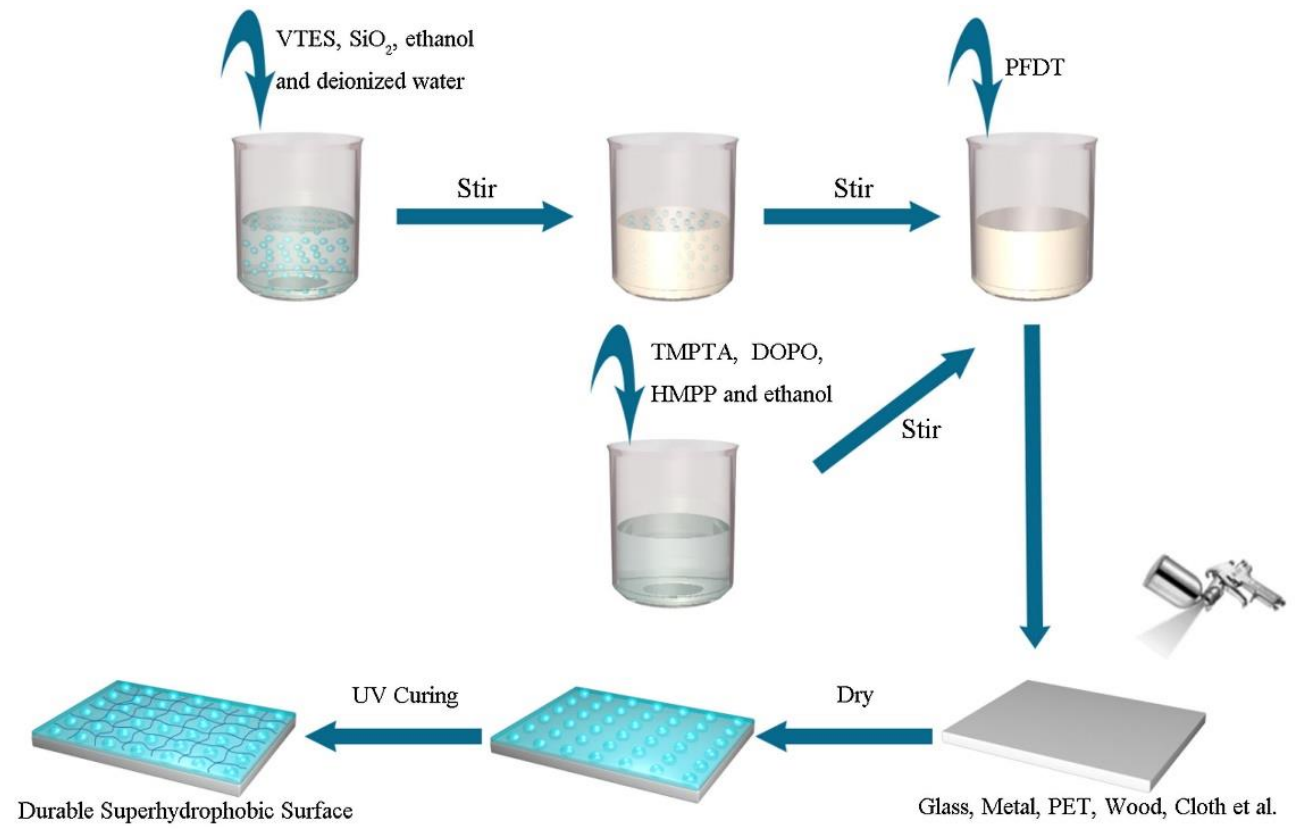

Figure 17. Preparation procedure for PVDT coatings on various substrates. Reprinted with permission from [143]; Copyright 2019 Elsevier.

\section{Conclusions and Outlook}

Superhydrophobic coatings have high potential for industrial applications and thus, receive enormous attention. Due to their specific properties, including self-cleaning, antifogging, drag-reduction, corrosion resistance, anti-icing and icephobic properties, the fields of their application are expected to expand in the future. This paper provides a comprehensive review of superhydrophobic coatings in the application fields of automobile, marine, aircraft, solar energy and architecture-buildings based on the requirement for prominent functionalities and performance conformities. The review also discusses the 
existing bottlenecks that limit industrial application and future trends in the improved performance conformities of superhydrophobic coatings. Firstly, some fundamental theories of the wetting behavior of surfaces were described, then detailed discussions on preparation methods and prominent and required functionalities and performance conformities of superhydrophobic coatings in several key application fields were deployed. The review provides a reference for and insight into the protection and high performances of various substrates by endowing their substrates with superhydrophobicity and other multifunctional properties applied in different fields.

Long-lasting superhydrophobic coatings hold promise for practical applications in daily life and industries. However, superhydrophobic coatings are difficult to implement in industries due to poor durability [43], especially weak mechanical property, although large quantities of articles on fabricating robust and durable superhydrophobic coatings have been published. Double hierarchical structures are generally considered essential to fabricate superhydrophobic coatings, but these micro/nano structures are fragile and easily destroyed. Nevertheless, the research studied by Aytug et al. [115] showed an interesting outcome. They fabricated a three-dimensionally interconnected nanoporous coating on glass platforms, which possessed excellent superhydrophobicity, anti-reflectivity, self-cleanability and mechanical durability. The novel method achieved technological breakthroughs in fabrication of superhydrophobic coatings with only nano-structure roughness. This proves that new approaches may always be worth exploring and we do not need to be restricted by an existing mind-set for seeking resolutions to the issues associated with current superhydrophobic coatings.

In addition, lack of effective evaluation methods also impedes the practical development of durable and robust superhydrophobic coatings. Many studies have employed various approaches to evaluate the mechanical strengths of superhydrophobic coatings, e.g., sandpaper abrasion, adhesive tape peeling, water-jet impact, knife scratch, finger abrasion, etc. However, there is a lack of standardized evaluation methods for the durability of superhydrophobic coatings. Some operations may even be be misleading, such as sandpaper abrasion, which removes the top rough surface and exposes new roughness, thereby maintaining the superhydrophobicity. Future works should focus more on the improvement of durability and establishment of better durability assessment methods, which should simulate the real conditions that the superhydrophobic coatings are exposed to.

Author Contributions: Writing—original draft preparation, Y.B.; writing—review and editing, Y.B., H.Z. (Hui Zhang), H.Z. (Haiping Zhang), and J.Z.; supervision, H.Z. (Hui Zhang), J.Z., and H.Z. (Haiping Zhang); project administration, J.Z., H.Z. (Hui Zhang), and Y.S.; funding acquisition, H.Z. (Hui Zhang). All authors have read and agreed to the published version of the manuscript.

Funding: The authors are grateful to the Natural Sciences and Engineering Research Council of Canada (Discovery Grant RGPIN-2018-06256) for supporting this work.

Conflicts of Interest: The authors declare no conflict of interest.

\section{References}

1. Feng, L.; Zhang, H.; Wang, Z.; Liu, Y. Superhydrophobic aluminum alloy surface: Fabrication, structure, and corrosion resistance. Colloid Surf. A-Physicochem. Eng. Asp. 2014, 441, 319-325. [CrossRef]

2. Cengiz, U.; Cansoy, C.E. Applicability of Cassie-Baxter equation for superhydrophobic fluoropolymer silica composite films. Appl. Surf. Sci. 2015, 335, 99-106. [CrossRef]

3. Qian, Z.; Wang, S.; Ye, X.; Liu, Z.; Wu, Z. Corrosion resistance and wetting properties of silica-based superhydrophobic coatings on AZ31B Mg alloy surfaces. Appl. Surf. Sci. 2018, 453, 1-10. [CrossRef]

4. Wenzel, R.N. Resistance of solid surfaces to wetting by water. Ind. Eng. Chem. 1936, 28, 988-994. [CrossRef]

5. Cassie, A.B.D.; Baxter, S. Wettability of porous surfaces. Trans. Faraday Soc. 1944, 40, 546-551. [CrossRef]

6. Vazirinasab, E.; Jafari, R.; Momen, G. Application of superhydrophobic coatings as a corrosion barrier: A review. Surf. Coat. Technol. 2017, 341, 40-56. [CrossRef]

7. Wang, T.; Chang, L.; Yang, S.; Jia, Y.; Wong, C. Hydrophobic properties of biomorphic carbon surfaces prepared by sintering lotus leaves. Ceram. Int. 2013, 39, 8165-8172. [CrossRef] 
8. Liu, M.; Hou, Y.; Li, J.; Tie, L.; Peng, Y.; Guo, Z. Inorganic adhesives for robust, self-healing, superhydrophobic surfaces. J. Mater. Chem. A 2017, 5, 19297-19305. [CrossRef]

9. Nishimoto, S.; Bhushan, B. Bioinspired self-cleaning surfaces with superhydrophobicity, superoleophobicity, and superhydrophilicity. RSC Adv. 2012, 3, 671-690. [CrossRef]

10. Li, H.; Yu, S. A robust superhydrophobic surface and origins of its self-cleaning properties. Appl. Surf. Sci. 2017, 420, 336-345. [CrossRef]

11. Furstner, R.; Barthlott, W.; Neinhuis, C.; Walzel, P. Wetting and self-cleaning properties of artificial superhydrophobic surfaces. Langmuir 2005, 21, 956-961. [CrossRef] [PubMed]

12. Xiang, T.; Han, Y.; Guo, Z.; Wang, R.; Zheng, S.; Li, S.; Li, C.; Dai, X. Fabrication of Inherent Anticorrosion Superhydrophobic Surfaces on Metals. ACS Sustain. Chem. Eng. 2018, 6, 5598-5606. [CrossRef]

13. Hwang, G.B.; Patir, A.; Page, K.; Lu, Y.; Allan, E.; Parkin, I.P. Buoyancy increase and drag-reduction through a simple superhydrophobic coating. Nanoscale 2017, 9, 7588-7594. [CrossRef] [PubMed]

14. Peng, C.W.; Chang, K.C.; Weng, C.J.; Lai, M.C.; Hsu, C.H.; Hsu, S.C.; Hsu, Y.Y.; Hung, W.I.; Wei, Y.; Yeh, J.M. Nano-casting technique to prepare polyaniline surface with biomimetic superhydrophobic structures for anticorrosion application. Electrochim. Acta 2013, 95, 192-199. [CrossRef]

15. Xiang, T.; Zhang, M.; Li, C.; Zheng, S.; Ding, S.; Wang, J.; Dong, C.; Yang, L. A facile method for fabrication of superhydrophobic surface with controllable water adhesion and its applications. J. Alloys Compd. 2017, 704, 170-179. [CrossRef]

16. Jie, H.; Xu, Q.; Wei, L.; Min, Y. Etching and heating treatment combined approach for superhydrophobic surface on brass substrates and the consequent corrosion resistance. Corros. Sci. 2016, 102, 251-258. [CrossRef]

17. Zheng, S.; Cheng, L.; Fu, Q.; Wei, H.; Xiang, T.; Qi, W.; Du, M.; Liu, X.; Zhong, C. Development of stable superhydrophobic coatings on aluminum surface for corrosion-resistant, self-cleaning, and anti-icing applications. Mater. Des. 2016, 93, 261-270. [CrossRef]

18. Seifzadeh, D.; Farhoudi, L. Electroless Co-P plating on magnesium alloy and its anti-corrosion properties. Surf. Eng. 2016, 32, 348-355. [CrossRef]

19. Mao, J.; Ge, M.; Huang, J.; Lai, Y.; Tang, Y. Constructing multifunctional MOF@rGO hydro-/aerogels by the self-assembly process for customized water remediation. J. Mater. Chem. A 2017, 5, 11873-11881. [CrossRef]

20. Guzman, E.; Rubio, R.G.; Ortega, F. A closer physico-chemical look to the Layer-by-Layer electrostatic self-assembly of polyelectrolyte multilayers. Adv. Colloid Interface Sci. 2020, 282, 102197. [CrossRef]

21. Rezayi, T.; Entezari, M.H. Achieving to a superhydrophobic glass with high transparency by a simple sol-gel-dip-coating method. Surf. Coat. Technol. 2015, 276, 557-564. [CrossRef]

22. Sutar, R.S.; Latthe, S.S.; Bhosale, A.K.; Xing, R.; Liu, S. Durable self-cleaning superhydrophobic coating of $\mathrm{SiO}_{2}-\mathrm{cyanoacrylate}$ adhesive via facile dip coat technique. Macromol. Symp. 2019, 387, 1800218. [CrossRef]

23. Zhang, X.; Liu, Z.; Li, Y.; Wang, C.; Zhu, Y.; Wang, H.; Wang, J. Robust superhydrophobic epoxy composite coating prepared by dual interfacial enhancement. Chem. Eng. J. 2019, 371, 276-285. [CrossRef]

24. Li, D.; Wang, H.; Liu, Y.; Wei, D.; Zhao, Z. Large-scale fabrication of durable and robust super-hydrophobic spray coatings with excellent repairable and anti-corrosion performance. Chem. Eng. J. 2019, 367, 169-179. [CrossRef]

25. Nguyen-Tri, P.; Tran, H.N.; Plamondon, C.O.; Tuduri, L.; Vo, D.-V.N.; Nanda, S.; Mishra, A.; Chao, H.-P.; Bajpai, A.K. Recent progress in the preparation, properties and applications of superhydrophobic nano-based coatings and surfaces: A review. Prog. Org. Coat. 2019, 132, 235-256. [CrossRef]

26. Jacobson, M.Z.; Jadhav, V. World estimates of PV optimal tilt angles and ratios of sunlight incident upon tilted and tracked PV panels relative to horizontal panels. Sol. Energy 2018, 169, 55-66. [CrossRef]

27. Roslizar, A.; Dottermusch, S.; Schmager, R.; Guttmann, M.; Gomard, G.; Hoelscher, H.; Richards, B.S.; Paetzold, U.W. Hotembossed microcone-textured fluoropolymer as self-cleaning and anti-reflective photovoltaic module covers. Sol. Energy Mater. Sol. Cells 2020, 214, 110582. [CrossRef]

28. Sindagi, S.; Vijayakumar, R. Succinct review of MBDR/BDR technique in reducing ship's drag. Ships Offshore Struct. 2020, 1-12. [CrossRef]

29. Zhang, G.Q.; Schluter, J.; Hu, X. Parametric investigation of drag reduction formarine vessels using air-filled dimpled surfaces. Ships Offshore Struct. 2018, 13, 244-255. [CrossRef]

30. Basu, S.; Hanh, B.M.; Chua, J.Q.I.; Daniel, D.; Ismail, M.H.; Marchioro, M.; Amini, S.; Rice, S.A.; Miserez, A. Green biolubricant infused slippery surfaces to combat marine biofouling. J. Colloid Interface Sci. 2020, 568, 185-197. [CrossRef]

31. Cirisano, F.; Benedetti, A.; Liggieri, L.; Ravera, F.; Santini, E.; Ferrari, M. Amphiphobic coatings for antifouling in marine environment. Colloid Surf. A-Physicochem. Eng. Asp. 2016, 505, 158-164. [CrossRef]

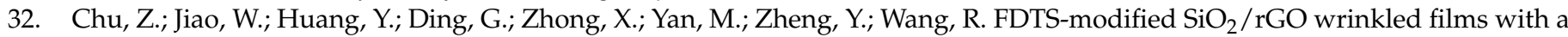
micro-nanoscale hierarchical structure and anti-icing/deicing properties under condensation condition. Adv. Mater. Interfaces 2020, 7, 1901446. [CrossRef]

33. Huang, X.; Tepylo, N.; Pommier-Budinger, V.; Budinger, M.; Bonaccurso, E.; Villedieu, P.; Bennani, L. A survey of icephobic coatings and their potential use in a hybrid coating/active ice protection system for aerospace applications. Prog. Aeosp. Sci. 2019, 105, 74-97. [CrossRef] 
34. Ahmad, A.A.; Al-Bataineh, Q.M.; Alsaad, A.M.; Samara, T.O.; Al-izzy, K.A. Optical properties of hydrophobic ZnO nano-structure based on antireflective coatings of $\mathrm{ZnO} / \mathrm{TiO}_{2} / \mathrm{SiO}_{2}$ thin films. Phys. B 2020, 593, 412263. [CrossRef]

35. Chen, D.G. Anti-reflection (AR) coatings made by sol-gel processes: A review. Sol. Energy Mater. Sol. Cells 2001, 68, 313-336. [CrossRef]

36. Chen, Y.; Zhang, Y.B.; Shi, L.; Li, J.; Xin, Y.; Yang, T.T.; Guo, Z.G. Transparent superhydrophobic/superhydrophilic coatings for self-cleaning and anti-fogging. Appl. Phys. Lett. 2012, 101, 033701. [CrossRef]

37. Duran, I.R.; Laroche, G. Water drop-surface interactions as the basis for the design of anti-fogging surfaces: Theory, practice, and applications trends. Adv. Colloid Interface Sci. 2019, 263, 68-94. [CrossRef]

38. Duran, I.R.; Laroche, G. Current trends, challenges, and perspectives of anti-fogging technology: Surface and material design, fabrication strategies, and beyond. Prog. Mater. Sci. 2019, 99, 106-186. [CrossRef]

39. Karunakaran, R.G.; Lu, C.H.; Zhang, Z.; Yang, S. Highly transparent superhydrophobic surfaces from the coassembly of nanoparticles ( $\leq 100 \mathrm{~nm})$. Langmuir 2011, 27, 4594-4602. [CrossRef]

40. Nakajima, A.; Abe, K.; Hashimoto, K.; Watanabe, T. Preparation of hard super-hydrophobic films with visible light transmission. Thin Solid Films 2000, 376, 140-143. [CrossRef]

41. Shang, Q.; Zhou, Y. Fabrication of transparent superhydrophobic porous silica coating for self-cleaning and anti-fogging. Ceram. Int. 2016, 42, 8706-8712. [CrossRef]

42. Son, T.; Yang, E.; Yu, E.; Oh, K.H.; Moon, M.W.; Kim, H.Y. Effects of surface nanostructures on self-cleaning and anti-fogging characteristics of transparent glass. J. Mech. Sci. Technol. 2017, 31, 5407-5414. [CrossRef]

43. Simpson, J.T.; Hunter, S.R.; Aytug, T. Superhydrophobic materials and coatings: A review. Rep. Prog. Phys. 2015, 78, 086501. [CrossRef] [PubMed]

44. Jafari, R.; Farzaneh, M. A simple method to create superhydrophobic aluminium surfaces. Mater. Sci. Forum 2012, 706, 2874-2879. [CrossRef]

45. Basu, B.J.; Kumar, V.D.; Anandan, C. Surface studies on superhydrophobic and oleophobic polydimethylsiloxane-silica nanocomposite coating system. Appl. Surf. Sci. 2012, 261, 807-814. [CrossRef]

46. Liu, X.; Xu, Y.; Ben, K.; Chen, Z.; Wang, Y.; Guan, Z. Transparent, durable and thermally stable PDMS-derived superhydrophobic surfaces. Appl. Surf. Sci. 2015, 339, 94-101. [CrossRef]

47. Gao, S.; Dong, X.; Huang, J.; Li, S.; Li, Y.; Chen, Z.; Lai, Y. Rational construction of highly transparent superhydrophobic coatings based on a non-particle, fluorine-free and water-rich system for versatile oil-water separation. Chem. Eng. J. 2017, 333, 621-629. [CrossRef]

48. Syafiq, A.; Vengadaesvaran, B.; Ahmed, U.; Rahim, N.A.; Ramesh, S. Facile synthesize of transparent hydrophobic nano-CaCO 3 based coatings for self-cleaning and anti-fogging. Mater. Chem. Phys. 2019, 239, 121913. [CrossRef]

49. Patil, A.; Ferritto, M.S. Polymers for Personal Care and Cosmetics: Overview; ACS Symposium Series; ACS Publications: Washington, DC, USA, 2013; Volume 1148, pp. 3-11.

50. Qing, Y.; Yang, C.; Sun, Y.; Zheng, Y.; Wang, X.; Shang, Y.; Wang, L.; Liu, C. Facile fabrication of superhydrophobic surfaces with corrosion resistance by nanocomposite coating of $\mathrm{TiO}_{2}$ and polydimethylsiloxane. Colloid Surf. A-Physicochem. Eng. Asp. 2015, 484, 471-477. [CrossRef]

51. Lai, Y.; Tang, Y.; Gong, J.; Gong, D.; Chi, L.; Lin, C.; Chen, Z. Transparent superhydrophobic/superhydrophilic TiO ${ }_{2}$-based coatings for self-cleaning and anti-fogging. J. Mater. Chem. 2012, 22, 7420-7426. [CrossRef]

52. Li, X.; He, J. In situ assembly of raspberry- and mulberry-like silica nanospheres toward antireflective and antifogging coatings. ACS Appl. Mater. Interfaces 2012, 4, 2204-2211. [CrossRef] [PubMed]

53. Hooda, A.; Goyat, M.S.; Pandey, J.K.; Kumar, A.; Gupta, R. A review on fundamentals, constraints and fabrication techniques of superhydrophobic coatings. Prog. Org. Coat. 2020, 142, 105557. [CrossRef]

54. Wang, J.; Li, D.; Liu, Q.; Yin, X.; Zhang, Y.; Jing, X.; Zhang, M. Fabrication of hydrophobic surface with hierarchical structure on $\mathrm{Mg}$ alloy and its corrosion resistance. Electrochim. Acta 2010, 55, 6897-6906. [CrossRef]

55. Qing, Y.; Yang, C.; Hu, C.; Zheng, Y.; Liu, C. A facile method to prepare superhydrophobic fluorinated polysiloxane/ZnO nanocomposite coatings with corrosion resistance. Appl. Surf. Sci. 2015, 326, 48-54. [CrossRef]

56. Liu, C.; Su, F.; Liang, J. Facile fabrication of a robust and corrosion resistant superhydrophobic aluminum alloy surface by a novel method. RSC Adv. 2014, 4, 55556-55564. [CrossRef]

57. Isimjan, T.T.; Wang, T.; Rohani, S. A novel method to prepare superhydrophobic, UV resistance and anti-corrosion steel surface. Chem. Eng. J. 2012, 210, 182-187. [CrossRef]

58. Wu, L.K.; Zhang, X.F.; Hu, J.M. Corrosion protection of mild steel by one-step electrodeposition of superhydrophobic silica film. Corros. Sci. 2014, 85, 482-487. [CrossRef]

59. Ran, M.; Zheng, W.; Wang, H. Fabrication of superhydrophobic surfaces for corrosion protection: A review. Mater. Sci. Technol. 2019, 35, 313-326. [CrossRef]

60. Sun, W.; Tan, A.W.Y.; Marinescu, I.; Toh, W.Q.; Liu, E. Adhesion, tribological and corrosion properties of cold-sprayed CoCrMo and Ti6Al4V coatings on 6061-T651 Al alloy. Surf. Coat. Technol. 2017, 326, 291-298. [CrossRef]

61. Chen, Z.; Hao, L.; Duan, M.; Chen, C. Electrodeposition fabrication of Co-based superhydrophobic powder coatings in nonaqueous electrolyte. Appl. Phys. A-Mater. Sci. Process. 2013, 111, 581-585. [CrossRef] 
62. Lv, Z.; Yu, S.; Song, K.; Zhou, X.; Yin, X. Fabrication of a leaf-like superhydrophobic CuO coating on 6061Al with good self-cleaning, mechanical and chemical stability. Ceram. Int. 2020, 46, 14872-14883. [CrossRef]

63. Gao, R.; Wang, J.; Zhang, X.; Yan, H.; Yang, W.; Liu, Q.; Zhang, M.; Liu, L.; Takahashi, K. Fabrication of superhydrophobic magnesium alloy through the oxidation of hydrogen peroxide. Colloid Surf. A-Physicochem. Eng. Asp. 2013, 436, 906-911. [CrossRef]

64. Chu, Q.; Liang, J.; Hao, J. Facile fabrication of a robust super-hydrophobic surface on magnesium alloy. Colloid Surf. A-Physicochem. Eng. Asp. 2014, 443, 118-122. [CrossRef]

65. Dong, H.; Cheng, M.; Zhang, Y.; Wei, H.; Shi, F. Extraordinary drag-reducing effect of a superhydrophobic coating on a macroscopic model ship at high speed. J. Mater. Chem. 2013, 1, 5886-5891. [CrossRef]

66. Ferrari, M.; Cirisano, F.; Carmen Moran, M. Regenerable superhydrophobic coatings for biomedical fabrics. Coatings 2020, 10, 578. [CrossRef]

67. Cheng, M.; Zhang, S.; Dong, H.; Han, S.; Wei, H.; Shi, F. Improving the durability of a drag-reducing nanocoating by enhancing its mechanical stability. ACS Appl. Mater. Interfaces 2015, 7, 4275-4282. [CrossRef]

68. Ejenstam, L.; Ovaskainen, L.; Rodriguez-Meizoso, I.; Wagberg, L.; Pan, J.; Swerin, A.; Claesson, P.M. The effect of superhydrophobic wetting state on corrosion protection-The AKD example. J. Colloid Interface Sci. 2013, 412, 56-64. [CrossRef]

69. Zhang, B.; Zhu, Q.; Li, Y.; Hou, B. Facile fluorine-free one step fabrication of superhydrophobic aluminum surface towards self-cleaning and marine anticorrosion. Chem. Eng. J. 2018, 352, 625-633. [CrossRef]

70. Xue, C.; Jia, S.; Zhang, J.; Ma, J. Large-area fabrication of superhydrophobic surfaces for practical applications: An overview. Sci. Technol. Adv. Mater. 2010, 11, 033002. [CrossRef]

71. Xue, C.; Jia, S.; Zhang, J.; Tian, L. Superhydrophobic surfaces on cotton textiles by complex coating of silica nanoparticles and hydrophobization. Thin Solid Films 2009, 517, 4593-4598. [CrossRef]

72. Ferrari, M.; Benedetti, A.; Cirisano, F. Superhydrophobic coatings from recyclable materials for protection in a real sea environment. Coatings 2019, 9, 303. [CrossRef]

73. Momber, A.W.; Plagemann, P.; Stenzel, V. The adhesion of corrosion protection coating systems for offshore wind power constructions after three years under offshore exposure. Int. J. Adhes. Adhes. 2016, 65, 96-101. [CrossRef]

74. Lopez-Ortega, A.; Bayon, R.; Luis Arana, J. Evaluation of protective coatings for high-corrosivity category atmospheres in offshore applications. Materials 2019, 12, 1325. [CrossRef] [PubMed]

75. Kirchgeorg, T.; Weinberg, I.; Hornig, M.; Baier, R.; Schmid, M.J.; Brockmeyer, B. Emissions from corrosion protection systems of offshore wind farms: Evaluation of the potential impact on the marine environment. Mar. Pollut. Bull. 2018, 136, 257-268. [CrossRef] [PubMed]

76. Chaliampalias, D.; Vourlias, G.; Pavlidou, E.; Stergioudis, G.; Skolianos, S.; Chrissafis, K. High temperature oxidation and corrosion in marine environments of thermal spray deposited coatings. Appl. Surf. Sci. 2008, 255, 3104-3111. [CrossRef]

77. Chen, X.; Yuan, J.; Huang, J.; Ren, K.; Liu, Y.; Lu, S.; Li, H. Large-scale fabrication of superhydrophobic polyurethane/ nano- $\mathrm{Al}_{2} \mathrm{O}_{3}$ coatings by suspension flame spraying for anti-corrosion applications. Appl. Surf. Sci. 2014, 311, 864-869. [CrossRef]

78. Fahim, J.; Ghayour, H.; Hadavi, S.M.M.; Tabrizi, S.A.H. Fabrication of Superhydrophobic Al5083 Aluminum Alloy for Marine Applications. Prot. Met. Phys. Chem. Surf. 2018, 54, 899-908. [CrossRef]

79. Liu, Y.; Li, S.; Zhang, J.; Liu, J.; Han, Z.; Ren, L. Corrosion inhibition of biomimetic super-hydrophobic electrodeposition coatings on copper substrate. Corros. Sci. 2015, 94, 190-196. [CrossRef]

80. Su, F.; Yao, K.; Liu, C.; Huang, P. Rapid fabrication of corrosion resistant and superhydrophobic cobalt coating by a one-step electrodeposition. J. Electrochem. Soc. 2013, 160, 593-599. [CrossRef]

81. Qin, L.; Kang, Z. One-step electrodeposition process to fabricate superhydrophobic surface with improved anticorrosion property on magnesium alloy. Mater. Lett. 2014, 137, 210-213.

82. Su, F.; Yao, K. Facile Fabrication of superhydrophobic surface with excellent mechanical abrasion and corrosion resistance on copper substrate by a novel method. ACS Appl. Mater. Interfaces 2014, 6, 8762-8770. [CrossRef] [PubMed]

83. Benedetti, A.; Cirisano, F.; Delucchi, M.; Faimali, M.; Ferrari, M. Potentiodynamic study of Al-Mg alloy with superhydrophobic coating in photobiologically active/not active natural seawater. Colloid Surf. B-Biointerfaces 2016, 137, 167-175. [CrossRef] [PubMed]

84. Ferrari, M.; Benedetti, A.; Santini, E.; Ravera, F.; Liggieri, L.; Guzman, E.; Cirisano, F. Biofouling control by superhydrophobic surfaces in shallow euphotic seawater. Colloid Surf. A-Physicochem. Eng. Asp. 2015, 480, 369-375. [CrossRef]

85. Piscitelli, F.; Tescione, F.; Mazzola, L.; Bruno, G.; Lavorgna, M. On a simplified method to produce hydrophobic coatings for aeronautical applications. Appl. Surf. Sci. 2019, 472, 71-81. [CrossRef]

86. Meuler, A.J.; Smith, J.D.; Varanasi, K.K.; Mabry, J.M.; Mckinley, G.H.; Cohen, R.E. Relationships between water wettability and ice adhesion. ACS Appl. Mater. Interfaces. 2010, 2, 3100-3110. [CrossRef] [PubMed]

87. Mishchenko, L.; Hatton, B.; Bahadur, V.; Taylor, J.A.; Krupenkin, T.; Aizenberg, J. Design of ice-free nanostructured surfaces based on repulsion of impacting water droplets. ACS Nano 2010, 4, 7699-7707. [CrossRef] [PubMed]

88. Politovich, M.K. Aircraft Icing. Encycl. Atmos. Sci. 2003, 358, 68-75.

89. Zhan, X.; Yan, Y.; Zhang, Q.; Chen, F. A novel superhydrophobic hybrid nanocomposite material prepared by surface-initiated AGET ATRP and its anti-icing properties. J. Mater. Chem. A 2014, 2, 9390-9399. [CrossRef] 
90. Shen, Y.; Tao, J.; Tao, H.; Chen, S.; Pan, L.; Wang, T. Anti-icing potential of superhydrophobic Ti6Al4V surfaces: Ice nucleation and growth. Langmuir 2015, 31, 10799-10806. [CrossRef]

91. Menini, R.; Ghalmi, Z.; Farzaneh, M. Highly resistant icephobic coatings on aluminum alloys. Cold Reg. Sci. Technol. 2011, 65, 65-69. [CrossRef]

92. Momen, C.; Farzaneh, M. Facile approach in the development of icephobic hierarchically textured coatings as corrosion barrier. Appl. Surf. Sci. 2014, 299, 41-46. [CrossRef]

93. Ruan, M.; Zhan, Y.; Wu, Y.; Wang, X.; Li, W.; Chen, Y.; Wei, M.; Wang, X.; Deng, X. Preparation of PTFE/PDMS superhydrophobic coating and its anti-icing performance. RSC Adv. 2017, 7, 41339-41344. [CrossRef]

94. Xing, W.; Li, Z.; Yang, H.; Li, X.; Wang, X.; Li, N. Anti-icing aluminum alloy surface with multi-level micro-nano textures constructed by picosecond laser. Mater. Des. 2019, 183, 108156. [CrossRef]

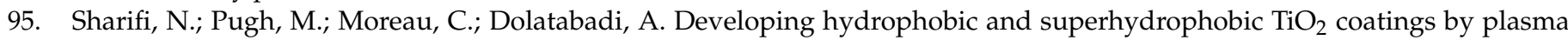
spraying. Surf. Coat. Technol. 2016, 289, 29-36. [CrossRef]

96. Sharifi, N.; Dolatabadi, A.; Pugh, M.; Moreau, C. Anti-icing performance and durability of suspension plasma sprayed TiO 2 coatings. Cold Reg. Sci. Technol. 2019, 159, 1-12. [CrossRef]

97. Liu, J.; Janjua, Z.A.; Roe, M.; Xu, F.; Turnbull, B.; Choi, K.; Hou, X. Super-hydrophobic/icephobic coatings based on silica nanoparticles modified by self-assembled monolayers. Nanomaterials 2016, 6, 232. [CrossRef]

98. $\mathrm{Wu}, \mathrm{X}$;; Chen, Z. A mechanically robust transparent coating for anti-icing and self-cleaning applications. J. Mater. Chem. A 2018, 6, 16043-16052. [CrossRef]

99. Fu, R.; Fu, G.D. Polymeric nanomaterials from combined click chemistry and controlled radical polymerization. Polym. Chem. 2011, 2, 465-475. [CrossRef]

100. Kakwere, H.; Perrier, S. Design of complex polymeric architectures and nanostructured materials/hybrids by living radical polymerization of hydroxylated monomers. Polym. Chem. 2011, 2, 270-288. [CrossRef]

101. Jakubowski, W.; Matyjaszewski, K. Activator generated by electron transfer for atom transfer radical polymerization. Macromolecules 2005, 38, 4139-4146. [CrossRef]

102. Mozumder, M.S.; Mourad, A.I.; Pervez, H.; Surkatti, R. Recent developments in multifunctional coatings for solar panel applications: A review. Sol. Energy Mater. Sol. Cells 2019, 189, 75-102. [CrossRef]

103. Wang, P.; Xie, J.; Ni, L.; Wan, L.; Ou, K.; Zheng, L.; Sun, K. Reducing the effect of dust deposition on the generating efficiency of solar PV modules by super-hydrophobic films. Sol. Energy 2018, 169, 277-283. [CrossRef]

104. Soklic, A.; Tasbihi, M.; Kete, M.; Stangar, U.L. Deposition and possible influence of a self-cleaning thin $\mathrm{TiO}_{2} / \mathrm{SiO} 2$ film on a photovoltaic module efficiency. Catal. Today 2015, 252, 54-60. [CrossRef]

105. You, S.; Lim, Y.J.; Dai, Y.; Wang, C. On the temporal modelling of solar photovoltaic soiling: Energy and economic impacts in seven cities. Appl. Energy 2018, 228, 1136-1146. [CrossRef]

106. Sakhuja, M.; Son, J.; Yang, H.; Bhatia, C.S.; Danner, A.J. Outdoor performance and durability testing of antireflecting and self-cleaning glass for photovoltaic applications. Sol. Energy 2014, 110, 231-238. [CrossRef]

107. Sarkn, A.S.; Ekren, N.; Salam, A. A review of anti-reflection and self-cleaning coatings on photovoltaic panels. Sol. Energy 2020, 199, 63-73. [CrossRef]

108. Ferrari, M.; Cirisano, F. High transmittance and highly amphiphobic coatings for environmental protection of solar panels. Adv. Colloid Interface Sci. 2020, 286, 102309. [CrossRef]

109. Piliougine, M.; Canete, C.; Moreno, R.; Carretero, J.; Hirose, J.; Ogawa, S.; Sidrach-De-Cardona, M. Comparative analysis of energy produced by photovoltaic modules with anti-soiling coated surface in arid climates. Appl. Energy 2013, 112, 626-634. [CrossRef]

110. Zang, Z. Efficiency enhancement of $\mathrm{ZnO} / \mathrm{Cu}_{2} \mathrm{O}$ solar cells with well oriented and micrometer grain sized Cu2O films. Appl. Phys. Lett. 2018, 112, 042106. [CrossRef]

111. Zhang, L.; Pan, A.; Cai, R.; Lu, H. Indoor experiments of dust deposition reduction on solar cell covering glass by transparent super-hydrophobic coating with different tilt angles. Sol. Energy 2019, 188, 1146-1155. [CrossRef]

112. Liu, X.; Lu, X.; Wen, P.; Shu, X.; Chi, F. Synthesis of ultrasmall silica nanoparticles for application as deep-ultraviolet antireflection coatings. Appl. Surf. Sci. 2017, 420, 180-185. [CrossRef]

113. Chi, F.; Liu, D.; Wu, H.; Lei, J. Mechanically robust and self-cleaning antireflection coatings from nanoscale binding of hydrophobic silica nanoparticles. Sol. Energy Mater. Sol. Cells 2019, 200, 109939. [CrossRef]

114. Sutha, S.; Suresh, S.; Raj, B.; Ravi, K.R. Transparent alumina based superhydrophobic self-cleaning coatings for solar cell cover glass applications. Sol. Energy Mater. Sol. Cells 2017, 165, 128-137. [CrossRef]

115. Aytug, T.; Lupini, A.R.; Jellison, G.E.; Joshi, P.C.; Ivanov, I.H.; Liu, T.; Wang, P.; Menon, R.; Trejo, R.M.; Lara-Curzio, E.; et al. Monolithic graded-refractive-index glass-based antireflective coatings: Broadband/omnidirectional light harvesting and selfcleaning characteristics. J. Mater. Chem. C 2015, 3, 5440-5449. [CrossRef]

116. Luo, G.Q.; Jin, Z.; Dong, Y.; Huang, J.; Zhang, R.; Wang, J.; Li, M.; Shen, Q.; Zhang, L. Preparation and performance enhancements of wear-resistant, transparent $\mathrm{PU} / \mathrm{SiO}_{2}$ superhydrophobic coating. Surf. Eng. 2018, 34, 139-145. [CrossRef]

117. Pekez, J.; Lambic, M.; Stojadinovic, S. Materials for flat plat solar collectors. Metal. Int. 2013, 18, 77-80.

118. Amri, A.; Jiang, Z.T.; Pryor, T.; Yin, C.Y.; Djordjevic, S. Developments in the synthesis of flat plate solar selective absorber materials via sol-gel methods: A review. Renew. Sustain. Energy Rev. 2014, 36, 316-328. [CrossRef] 
119. Pandey, K.M.; Chaurasiya, R. A review on analysis and development of solar flat plate collector. Renew. Sustain. Energy Rev. 2017, 67, 641-650. [CrossRef]

120. Zhu, Y.; Shi, J.; Huang, Q.; Fang, Y.; Wang, L.; Xu, G. A superhydrophobic solar selective absorber used in a flat plate solar collector. RSC Adv. 2017, 7, 34125-34130. [CrossRef]

121. Gao, X.H.; Guo, Z.M.; Geng, Q.F.; Ma, P.J.; Liu, G. Enhanced absorptance of surface-textured tungsten thin film for solar absorber. Surf. Eng. 2016, 32, 840-845. [CrossRef]

122. Ma, P.J.; Geng, Q.F.; Gao, X.H.; Yang, S.; Gang, L. Aqueous chemical solution deposition of spinel $\mathrm{Cu}_{1.5} \mathrm{Mn}_{1.5} \mathrm{O}_{4} \mathrm{single} \mathrm{layer} \mathrm{films}$ for solar selective absorber. RSC Adv. 2016, 6, 54820-54829. [CrossRef]

123. Hegazy, A.A. Effect of dust accumulation on solar transmittance through glass covers of plate-type collectors. Renew. Energy 2001, 22, 525-540. [CrossRef]

124. Khoukhi, M.; Maruyama, S. Theoretical approach of a flat-plate solar collector taking into account the absorption and emission within glass cover layer. Sol. Energy 2006, 80, 787-794. [CrossRef]

125. Akhtar, N.; Mullick, S.C. Effect of absorption of solar radiation in glass-cover(s) on heat transfer coefficients in upward heat flow in single and double glazed flat-plate collectors. Int. J. Heat Mass Transf. 2012, 55, 125-132. [CrossRef]

126. Cappelletti, G.; Fermo, P.; Camiloni, M. Smart hybrid coatings for natural stones conservation. Prog. Org. Coat. 2015, 78, 511-516. [CrossRef]

127. Aslanidou, D.; Karapanagiotis, I.; Panayiotou, C. Tuning the wetting properties of siloxane-nanoparticle coatings to induce superhydrophobicity and superoleophobicity for stone protection. Mater. Des. 2016, 108, 736-744. [CrossRef]

128. Pino, F.; Fermo, P.; La Russa, M.; Ruffolo, S.; Comite, V.; Baghdachi, J.; Pecchioni, E.; Fratini, F.; Cappelletti, G. Advanced mortar coatings for cultural heritage protection. Durability towards prolonged UV and outdoor exposure. Environ. Sci. Pollut. Res. 2017, 24, 12608-12617. [CrossRef]

129. Lee, Y.; You, E.A.; Ha, Y.G. Transparent, self-cleaning and waterproof surfaces with tunable micro/nano dual-scale structures. Nanotechnology 2016, 27, 355701. [CrossRef]

130. Lin, H.; Wang, Y.; Gan, Y.; Hou, H.; Yin, J.; Jiang, X. Simultaneous formation of a self-wrinkled surface and silver nanoparticles on a functional photocuring coating. Langmuir 2015, 31, 11800-11808. [CrossRef]

131. Wang, F.; Xie, T.; Ou, J.; Xue, M.; Li, W. Cement based superhydrophobic coating with excellent robustness and solar reflective ability. J. Alloys Compd. 2020, 823, 153702. [CrossRef]

132. Chatzigrigoriou, A.; Karapanagiotis, I.; Poulios, I. Superhydrophobic coatings based on siloxane resin and calcium hydroxide nanoparticles for marble protection. Coatings 2020, 10, 334. [CrossRef]

133. Zhi, D.; Lu, Y.; Sathasivam, S.; Parkin, I.P.; Zhang, X. Large-scale fabrication of translucent and repairable superhydrophobic spray coatings with remarkable mechanical, chemical durability and UV resistance. J. Mater. Chem. A 2017, 5, 10622-10631. [CrossRef]

134. Tu, K.; Wang, X.; Kong, L.; Guan, H. Facile preparation of mechanically durable, self-healing and multifunctional superhydrophobic surfaces on solid wood. Mater. Des. 2018, 140, 30-36. [CrossRef]

135. Liu, Z.; Wang, H.; Zhang, X.; Lv, C.; Wang, C.; Zhu, Y. Robust and chemically stable superhydrophobic composite ceramic coating repellent even to hot water. Adv. Mater. Interfaces 2017, 4, 1601202. [CrossRef]

136. Zulfiqar, U.; Awais, M.; Hussain, S.Z.; Hussain, I.; Husain, S.W.; Subhani, T. Durable and self-healing superhydrophobic surfaces for building materials. Mater. Lett. 2017, 192, 56-59. [CrossRef]

137. Zhang, Y.; Xiao, Z.; Liu, C.; Yu, X. Durable superamphiphobic coatings from one-step electrostatic dusting. Soft Matter 2019, 15, 7374-7380. [CrossRef]

138. Guo, Q.; Zhou, C.; Ma, Z.; Yang, X. Fundamentals of $\mathrm{TiO}_{2}$ photocatalysis: Concepts, mechanisms, and challenges. Adv. Mater. 2019, 31, 1901997. [CrossRef] [PubMed]

139. Zhang, J.; Lin, W.; Zhu, C.; Lv, J.; Zhang, W.; Feng, J. Dark, infrared reflective, and superhydrophobic coatings by waterborne resins. Langmuir 2018, 34, 5600-5605. [CrossRef]

140. Wen, G.; Huang, J.; Guo, Z. Energy-effective superhydrophobic nanocoating based on recycled eggshell. Colloid Surf. APhysicochem. Eng. Asp. 2019, 568, 20-28. [CrossRef]

141. Zhu, C.; Lv, J.; Chen, L.; Lin, W.; Zhang, J.; Yang, J.; Feng, J. Dark, heat-reflective, anti-ice rain and superhydrophobic cement concrete surfaces. Constr. Build. Mater. 2019, 220, 21-28. [CrossRef]

142. Xue, X.; Ma, L.; D, H.; H, X.Y.; H, Y.C. One-pot chemo-enzymatic conversion of D-xylose to furfuralcohol by sequential dehydration with oxalic acid plus tin-based solid acid and bioreduction with whole-cells. Bioresour. Technol. 2018, 268, 292-299. [CrossRef] [PubMed]

143. Wang, F.; Guo, Z. Facile fabrication of ultraviolet light cured fluorinated polymer layer for smart superhydrophobic surface with excellent durability and flame retardancy. J. Colloid Interface Sci. 2019, 547, 153-161. [CrossRef] [PubMed]

144. Rotel, M.; Zahavi, J.; Tamir, S.; Buchman, A.; Dodiuk, H. Pre-bonding technology based on excimer laser surface treatment. Appl. Surf. Sci. 2000, 154, 610-616. [CrossRef] 